\title{
Coupling DSSAT and HYDRUS-1D for simulations of soil water dynamics in the soil-plant-atmosphere system
}

\author{
Vakhtang Shelia $^{1 *}$, Jirka Šimůnek ${ }^{2}$, Ken Boote $^{1}$, Gerrit Hoogenbooom ${ }^{1}$ \\ ${ }^{1}$ Department of Agricultural and Biological Engineering \& Institute for Sustainable Food Systems, University of Florida, Gainesville, \\ FL 32611, USA. \\ ${ }^{2}$ Department of Environmental Sciences, University of California Riverside, Riverside, CA, USA. \\ * Corresponding author. Tel.: (1) 352-392-1864 ext 259. E-mail: vakhtang.shelia@ufl.edu
}

\begin{abstract}
Accurate estimation of the soil water balance of the soil-plant-atmosphere system is key to determining the availability of water resources and their optimal management. Evapotranspiration and leaching are the main sinks of water from the system affecting soil water status and hence crop yield. The accuracy of soil water content and evapotranspiration simulations affects crop yield simulations as well. DSSAT is a suite of field-scale, process-based crop models to simulate crop growth and development. A "tipping bucket" water balance approach is currently used in DSSAT for soil hydrologic and water redistribution processes. By comparison, HYDRUS-1D is a hydrological model to simulate water flow in soils using numerical solutions of the Richards equation, but its approach to crop-related process modeling is rather limited. Both DSSAT and HYDRUS-1D have been widely used and tested in their separate areas of use. The objectives of our study were: (1) to couple HYDRUS-1D with DSSAT to simulate soil water dynamics, crop growth and yield, (2) to evaluate the coupled model using field experimental datasets distributed with DSSAT for different environments, and (3) to compare HYDRUS-1D simulations with those of the tipping bucket approach using the same datasets. Modularity in the software design of both DSSAT and HYDRUS-1D made it easy to couple the two models. The pairing provided the DSSAT interface an ability to use both the tipping bucket and HYDRUS-1D simulation approaches. The two approaches were evaluated in terms of their ability to estimate the soil water balance, especially soil water contents and evapotranspiration rates. Values of the $d$ index for volumetric water contents were 0.9 and 0.8 for the original and coupled models, respectively. Comparisons of simulations for the pod mass for four soybean and four peanut treatments showed relatively high $d$ index values for both models (0.94-0.99).
\end{abstract}

Keywords: System Modeling; Crop Growth; Soil water; Unsaturated zone; DSSAT; HYDRUS-1D.

\section{INTRODUCTION}

Accurate estimation of the soil water balance is important for determining the availability of water resources and their optimal management in agriculture, the major consumer of water. Process-based simulation models of complex systems such as the soil-plant-atmosphere continuum are invaluable tools for this purpose. They may be used to simulate in detail multiple processes of the real system to predict various state variables at every time step during the simulations. The processes of evapotranspiration and leaching are the main sinks of water in the soil-plant-atmosphere system affecting soil water status. Their correct simulation is a prerequisite for successful simulations of crop growth and yield since the accuracy of soil water content and evapotranspiration simulations affect the accuracy of simulated plant processes and crop yield. Comparing model simulation results with field observations, or with results of other models based on different conceptual approaches, may provide invaluable information on the performance of the model and reveal their strong and weak parts. This is an essential step also when selecting appropriate models for practical applications in water resources analyses and for estimation of crop yield components. Comparing a physically-based soil-plant-atmosphere model with a simpler model may provide information on how the models perform compared to each other. If a simpler model can simulate the required processes with sufficient accuracy, that model should be an attractive alternative to a more dataintensive, complex simulation model. Using a simple model may also minimize the need for a comprehensive data collection effort (Ines at al., 2001; Pachepsky et al., 2006).
Crop simulation models usually are based on mathematical equations that describe the basic flow and conversion processes of carbon, water, and nitrogen, and that are integrated hourly or daily to predict the time course of crop growth, nutrient uptake, and water use, and to predict final yield and other plant traits (e.g., Boote et al., 2010). The Cropping System Models (CSM) in the DSSAT software (Decision Support System for Agrotechnology Transfer) are particularly well suited for simulating various agricultural practices (Jones et al., 2003). DSSAT (version 4.6) integrates several crop system models, soil carbon and nitrogen models, a daily water dynamic model, and a range of crop/land management options to simulate crop growth/yield and environmental impacts. DSSAT has been used widely and successfully for crop yield simulations under different management strategies, for optimizing the use of various resources, for yield trend simulations under different soil and climate scenarios, for crop yield risk analysis (Gijsman et al., 2002b; Sarkar, 2009), for simulating corn yield and nitrogen cycling in a 50-year corn production experiment (Liu et al., 2010), and for many other applications. The software has also been applied to controlled tile drainage-subsurface irrigation systems (Liu et al., 2011). Hence, DSSAT is particularly useful for predicting the short-, medium-, and long-term impacts of specific land management practices on crop yield, soil water storage, and nitrate-N leaching losses (Boote et al., 2010; Gheysari et al., 2009; Mullen et al., 2009).

The DSSAT Cropping System Model (CSM) (Jones et al., 2003; Hoogenboom et al., 2015) is a suite of field-scale, process-based crop models that have the capacity to simulate both crop and soil processes. They include the phenological devel- 
opment of crops and detailed growth components from emergence until harvest maturity on the basis of crop genetic coefficients, environmental (weather, soil) conditions, and management options. To simulate soil water flow and root water uptake in each individual soil layer, DSSAT CSM uses a onedimensional tipping bucket approach (Ritchie, 1998) that considers the soil profile to consist of a number of soil layers that are all homogeneous horizontally. The soil water balance model currently uses a tipping bucket approach for simulating soil hydrologic cycle and water redistribution for all crop models in CSM. The time step for the soil water balance and evapotranspiration $(E T)$ calculations is daily, which matches the timing of weather data inputs and daily plant dry matter growth (Ritchie, 1998). Boote et al. (2008) concluded that the tipping bucket soil water balance model in DSSAT generally works satisfactorily when the soil water-holding properties (a drained upper limit, $D U L$, and a lower limit of plant-extractable soil water, $L L$ ) are estimated properly, and when the rooting depth and root length distribution are predicted adequately. Nevertheless, the approach is inherently more approximate than the soil water flow calculations used in many hydrological models such as HYDRUS-1D, which can estimate soil moisture distribution in the soil profile with higher accuracy (Scanlon et al., 2002).

HYDRUS-1D (Šimůnek et al., 2008; 2016) is a widely used hydrological model that simulates water flow in onedimensional variably-saturated soils using numerical solutions of the Richards equation. The water flow equation incorporates a sink term to account for water uptake by plant roots. Root water uptake and transpiration are calculated using the formulation of Feddes et al. (1978). Evapotranspiration can be calculated using the Penman-Monteith equation. As compared to DSSAT, calculations in HYDRUS-1D are more physically based by allowing flow to be driven by pressure head differences, thus allowing for capillary flow and hence both upward or downward flow in the soil profile. The runoff calculations in HYDRUS-1D are also less empirical than in DSSAT. While DSSAT uses the modified curve number method of the United States Department of Agriculture, Soil Conservation Service (USDA-SCS) (Williams, 1991), HYDRUS-1D determines runoff as infiltration-excess water that is obtained by the numerical solution of the Richards equation for specified precipitation rates and soil hydraulic properties.

HYDRUS-1D has been used widely in many industrial and environmental applications, as well as for addressing many agricultural problems (Šimůnek et al., 2016). Examples of existing agricultural applications include irrigation management (Bristow et al., 2002; Dabach et al., 2015), drip and sprinkler irrigation design (Bristow et al., 2002; Gärdenäs et al., 2005; Hanson et al., 2008; Kandelous et al., 2012), studies of root water and nutrient uptake (Šimůnek and Hopmans, 2009; Vrugt et al., 2001a,b), among many others.

Both DSSAT and HYDRUS-1D have been used widely and tested separately, as well as coupled with other models. Several crop models describing relevant crop growth processes have been integrated successfully with hydrological models, such as DSSAT-RZWQM (Ma et al., 2006), DSSAT-SWAP (Dokoohaki et al., 2016), SWAT-MODFLOW (Sophocleous et al., 1999), and WOFOST-SWAP (van Walsum, 2011). Similarly, HYDRUS have been coupled successfully with existing crop and root growth models (e.g., Groenendyk et. al., 2012; Han et al., 2015; Hartmann et al., 2017; Li et al., 2014; Peña-Haro et al., 2012; Wang et al., 2014; Zhou et al., 2012). For example, Peña-Haro et al. (2012) integrated WOFOST, a crop growth and production model, with HYDRUS-1D as well as with MODFLOW-2000 (Harbaugh et al., 2000), the latter being a saturated flow model. The coupling was done using a combination of two different approaches: external coupling (through input/output data manipulation) and by using code wrapping. Peña-Haro et al. (2012) used OMS3 for wrapping WOFOST and PYTHON to write scripts. Groenendyk et al. (2012) coupled HYDRUS-1D with a generic crop growth model based on the plant growth module used in the WEPP model and then used the Ensemble Kalman Filter for assimilation of soil water content observations into the hydrologic model. The coupled approach was then tested for an irrigated wheat cropping experiment conducted at Maricopa, Arizona. Similarly, Hydrus-1D was coupled with MODFLOW-2000 for simulating hydrological processes at the large scale (Seo et al., 2007; Twarakavi et al., 2008).

The main objectives of this study were: a) to implement the flow routines from HYDRUS-1D into the DSSAT CSM crop models as a new option for simulating soil water dynamics, b) to evaluate the coupled model using field experimental datasets distributed with DSSAT for different environments, and c) to compare the performance of the HYDRUS-1D approach with the tipping bucket approach in DSSAT CSM using the same measured datasets. By integrating DSSAT with HYDRUS-1D, crop production simulations of DSSAT can be improved by using more accurate calculations of actual evaporation, transpiration, root water uptake, drainage, and water distributions in the soil profile using the Richards equation.

\section{MATERIALS AND METHODS DSSAT CSM}

The Cropping System Model (CSM) within DSSAT V4.6 (Hoogenboom et al., 2015; Jones et al., 2003) contains various crop models that are executed under the DSSAT shell. The crop models available are the CERES models for cereals (barley, maize, sorghum, millet, rice, and wheat), the CROPGRO models for legumes (dry bean, soybean, peanut, and chickpea), and additional models for root crops (cassava, potato) and other crops (sugarcane, tomato, sunflower, and pasture). The architecture differs from one model to another. Various controls and management scenarios can be invoked within the shell to simulate crop growth. The crop models can simulate single cropping, seasonal and sequential cropping systems.

The soil water balance in DSSAT is based on a formulation by Ritchie (1972, 1981a,b) using the concept of a drained upper limit $(D U L)$ and drained lower limit $(L L)$ for available soil water. The approach applies a simple water accounting procedure to each layer in the soil profile (Porter et al., 2004; Ritchie, 1985; 1998). Water from an upper layer cascades to lower layers, thereby mimicking the process of a series of linear reservoirs. Infiltration is calculated as the difference between rainfall/irrigation and runoff. Drainage between layers takes place if soil water present in the layer exceeds its water holding capacity. Drainage at the bottom of the soil profile is equal to the drainage flux from the bottom layer. Upward flow can be caused by root water uptake due to transpiration and by soil evaporation. Potential root water extraction depends on available soil water and the root length density of each layer in the soil. Actual transpiration is calculated using reduction factors as a function of the leaf area index and an energy extinction coefficient. Infiltration and runoff from rainfall or irrigation water are calculated using the USDA Soil Conservation Service runoff curve number method (Williams, 1991). The profile is assumed to be well drained and without any interaction with groundwater. Ritchie (1998) recommended the use of more appropriate modeling approaches for poorly 
drained conditions where the oxygen stress may affect crop growth.

Soil water balance processes include infiltration of rainfall and irrigation, runoff, soil evaporation, crop transpiration, root water uptake from the various soil layers, and drainage of water from the soil profile below the root zone (Boote et al., 2008). The soil is divided into a number of computational layers, up to a maximum of 20 . The water content of each layer varies between the lower limit of plant extractable soil water $[L L(j)]$, the drained upper limit $[D U L(j)]$, and the saturated soil water content $[S A T(j)]$, where $j$ is a soil layer number. If the water content of a given layer is above $D U L$, water will drain to the next layer based on the tipping bucket approach, using a profile-wide drainage coefficient $(S W C O N)$. If available, the saturated hydraulic conductivity $\left(K_{s}\right)$ of each soil layer can be entered to control vertical drainage from one layer to the next. This feature allows the soil to retain water above $D U L$ in layers that have a sufficiently low $K_{s}$, and which case soil layers may remain saturated long enough to cause root damage, reduced root water uptake, anoxia-induced stress, and lower $\mathrm{N}$ fixation. Water between $S A T$ and $D U L$ is available for root water uptake, subject to the anoxia-induced restriction that is triggered when the air-filled pore space falls below $2 \%$ of porosity (this value can be species-dependent). The DSSAT V4.6 software includes pedotransfer functions that compute $L L, D U L$, and $S A T$ from sand, silt, clay, soil organic carbon content, and bulk density. The pedotransfer functions are mostly those by Saxton et al. (1986) as described by Gijsman et al. (2002a).

The default option for computing potential evapotranspiration (PET, equivalent to $E T_{O}$ ) is the Priestley-Taylor method (Priestley and Taylor, 1972; Ritchie, 1985), primarily because it is less demanding for weather data and does not require daily wind speed or dewpoint temperature data as inputs. The FAO56 Penman-Monteith method is available if wind speed and dewpoint temperature are provided. The DSSAT crop models partition $P E T$ into potential plant transpiration $\left(E P_{O}\right)$ and potential soil evaporation $\left(E S_{O}\right)$ following Ritchie's (1972, 1985) approach, which considers the portion of net radiation that reaches the soil surface and can be used as latent energy to evaporate water from the soil surface if the soil is wet.

Actual soil evaporation $(E S)$ and plant transpiration $(E P)$ depend on the availability of water to meet potential rates. The current DSSAT CSM models allow calculations of ES using two soil evaporation methods: Suleiman-Ritchie (Ritchie et al., 2009) and the two-stage soil evaporation method of Ritchie (1985). The first approach is based on an equation derived from diffusion theory by Suleiman and Ritchie (Suleiman and Ritchie, 2003). The method is currently the default option for $E S$ computations in DSSAT CSM. The two-stage soil evaporation method computes $E S$ by assuming a constant rate during the energy-limited stage (Stage 1) and a falling-rate stage (Stage 2) that begins after the first stage loss has been met, during which $E S$ declines with the square root of time. Since neither the Suleiman-Ritchie method nor the two-stage soil evaporation method are considered to particularly accurate, improvements are still being considered.

Root water uptake must be computed before actual canopy transpiration $(E P)$ is computed. Potential root water uptake, $R W U(j)$, from each soil layer is a function of the root length density $(R L D)$ and the soil water content of that layer, and is calculated using a simplified approximation of radial flow to roots (Ritchie, 1985). The total soil water content (SWTD) and the total extractable water content $(S W X D)$ in the soil profile, among other variables, are calculated in the soil water balance module. $S W T D$ is equal to the water contents summed over all soil layers, i.e., $S W T D=\Sigma S W(j) \times D L A Y R(j)$, where $S W(j)$ is the volumetric water content in the $j$ th layer and $D L A Y R(j)$ is the thickness of the $j$ th layer. $S W X D$ is similarly equal to the extractable water contents summed over all soil layers, i.e., $S W X D=\Sigma(S W(j)-L L(j)) \times D L A Y R(j)$.

\section{HYDRUS-1D}

HYDRUS-1D is a physically-based, detailed hydrological model that simulates the relationships between soil, water, and weather, while using a sink term to account for water uptake by plant roots. The core of the model is the Richards onedimensional equation, which combines the Darcy-Buckingham law for the fluid flux with the continuity equation as follows:

$$
\frac{\partial \theta}{\partial t}=\frac{\partial}{\partial z}\left[K(h) \frac{\partial h}{\partial z}-K(h)\right]-S
$$

where $\theta$ is the volumetric water content $\left[\mathrm{L}^{3} \mathrm{~L}^{-3}\right], h$ is the pressure head [L], $K$ is the unsaturated hydraulic conductivity $\left[\mathrm{LT}^{-1}\right], z$ is the vertical coordinate positive upward [L], $t$ is time [T], and $S$ is root water uptake $\left[\mathrm{T}^{-1}\right]$.

HYDRUS-1D simulates soil water movement by considering spatial differences in the soil water potential in the soil profile. The governing equation is solved numerically using an implicit finite element scheme, which can be applied to both saturated and unsaturated conditions. The soil hydraulic functions are described using the analytical functions of van Genuchten-Mualem (Mualem, 1976; van Genuchten, 1980), among other formulations. HYDRUS-1D also considers, as needed, the effects of heat on water flow and the fate and transport of solutes in soils. Numerical solutions are provided for both flux or pressure head controlled boundary conditions at the top and bottom boundaries. The Penman-Monteith equation can be used to estimate potential evapotranspiration, $E T_{p}$. The HYDRUS-1D model uses the leaf area index (LAI) or the soil cover fraction $(S C)$ to separate potential evapotranspiration $\left(E T_{p}\right)$ into potential plant transpiration $\left(T_{p}\right)$ and potential evaporation $\left(E_{p}\right)$ of a partially covered soil. Reductions in $T_{p}$ and $E_{p}$ are calculated using a physically-based approach. Reductions in $T_{p}$ are obtained by using the Feddes et al. (1978) approach involving stress response functions, which depend on the type of crop. Reductions in $E_{p}$ are obtained directly from the numerical solution of the Richards equation by switching from a flux to a pressure head boundary condition when some limiting minimum pressure head is reached (e.g., $-150 \mathrm{~m}$ ). The effects of salinity and water/oxygen stress on actual transpiration can be considered to be either additive or multiplicative. Surface runoff is evaluated as infiltration-excess water calculated using the Richards equation for specified precipitation rates and soil hydraulic properties. Alternatively, infiltration-excess water can accumulate on the soil surface until a specified limit is reached, after which surface runoff is initiated. Field drainage to tile drains can be simulated using the Hooghoudt or Ernst equations for homogeneous and heterogeneous soil profiles, respectively. The bottom flux is calculated according to the selected bottom boundary conditions. Several water management scenarios can be modeled with HYDRUS-1D. For example, irrigation scheduling can be considered at fixed times or using a number of criteria that can trigger irrigation, such as its timing and depth of application. 


\section{Coupling the two models}

Accurate simulations of crop growth require proper integration of models for crop growth and water flow in the unsaturated zone. There are at least three different approaches for integrating independent external programs (Peña-Haro et al., 2012):

1) One could modify the original source code of the two models in order to have the coupled model within the same executable file.

2) The models could interact through their input/output files. However, if the variables of interest are not included in the default input or output files, this approach requires modifications to the original source codes of the two models.

3) The original code can be wrapped using a specialized software such as OMS3 (David et al., 2002), OpenMI (Gregersen, 2007), or PYTHON (www.python.org). This approach allows one to have access to all variables stored in a memory that is common to all programs.

In order to implement the HYDRUS-1D water flow routines into DSSAT, the routines were simplified first by removing the source code related to other processes, such as vapor flow and solute transport. After some reorganization, the remaining source code was then included directly into DSSAT CSM (both models are written in the Fortran language) to obtain one single executable program. The modular structure of DSSAT CSM (Jones et al., 2003) requires that all rate processes are calculated each day based on the state variables from the previous day, using a daily time step. Corresponding changes were implemented to inputs/outputs from HYDRUS-1D to DSSAT. Some variables had to be passed between the main program and the new subsystem. These data types were defined inside a new module and passed between the models.
Data transfer between the models can be summarized as follows (Fig. 1): DSSAT CSM calculates crop growth by taking as input the crop parameters and weather data. Among the output that DSSAT CSM generates, the following parameters were transferred to HYDRUS-1D as input: rooting depth, potential transpiration and evaporation, and irrigation and precipitation. Although DSSAT calculates root length distributions also, the current version of the coupled model assumes the HYDRUS1D approach in which the root distribution decreases linearly with depth from the soil surface to the bottom of the root zone. HYDRUS-1D then calculates soil water contents and actual transpiration and evaporation rates, integrated to a daily basis using the variable time-steps of HYDRUS-1D, which are then sent back to DSSAT CSM. Temporal and spatial discretizations are different in the two models and thus had to be synchronized. While HYDRUS-1D uses variable time steps and water stress periods are used, the structure of DSSAT CSM allows only daily time steps. Consequently, the two models exchange information on a daily time interval, while HYDRUS-1D carried out multiple time steps during this interval. Similarly as for the temporal discretization, HYDRUS-1D usually uses a much finer spatial discretization than DSSAT CSM. HYDRUS-1D outputs thus had to be averaged over multiple nodes, before information could be entered into DSSAT CSM.

The coupled DSSAT-HYDRUS-1D model is now able to simulate water flow using both the original tipping bucket approach as well as the HYDRUS-1D based numerical solution of the Richards equation. While HYDRUS-1D still focuses mostly on soil water, the Cropping System Model (CSM) from DSSAT deals nearly exclusively with plant related processes.

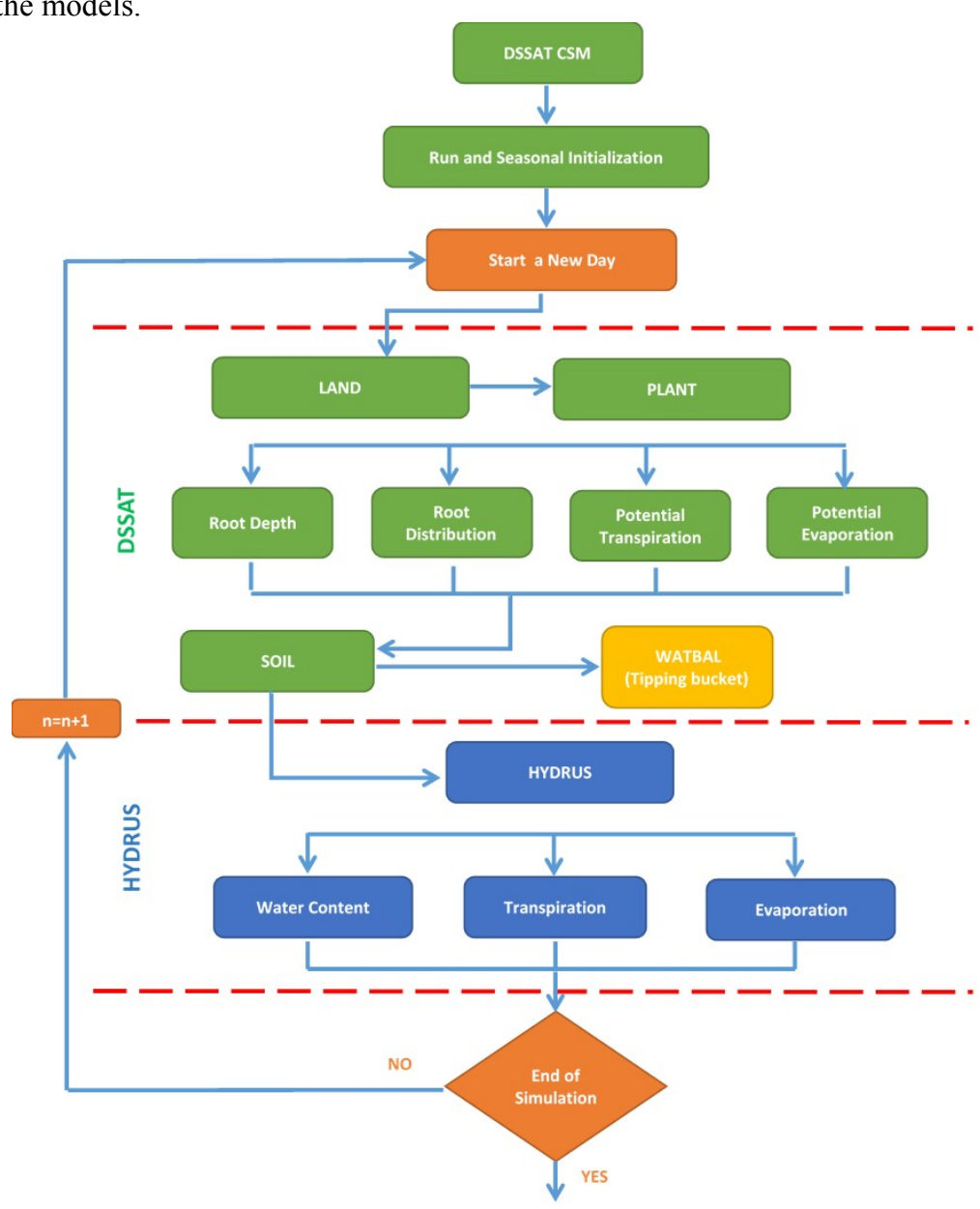

Fig. 1. Flowchart of the coupled DSSAT and HYDRUS-1D model. 


\section{Field experiments and data}

We used data from eight treatments of six experiments released with DSSAT V4.6 (Hoogenboom et al., 2015) for soybean and peanut to evaluate the coupled model. The field experiments were conducted between 1978 and 1990 by the University of Florida (UF), Gainesville, Florida, and Iowa State University (ISU), Ames, Iowa. The experimental field at UF was located at the campus far, with soil being characterized as a Millhopper fine sand soil (loamy, siliceous, hyperthemic Grossarenic Paleudults). The soil profiles in the DSSAT soil dataset (the SOIL.SOL file) are identified as IBSB910015 and IBPN910015 for the soybean and peanut experiments, respectively. Table 1 shows the soil physical and hydraulic properties of nine layers of the soil profile. These data are needed along with other soil properties such as soil albedo ( $S A L B$, fraction), the evaporation limit $(S L U 1, \mathrm{~mm})$, the drainage rate $(S L D R$, fraction day $\left.^{-1}\right)$, and the runoff curve number (SLRO) to simulate soil water dynamics in DSSAT. The drainage rate, $S L D R$, represents the fraction of water between the actual water content and the drained upper limit that drains from a soil layer in one day. For the given soil, these values were $S A L B=0.18$, $S L U 1=5.0 \mathrm{~mm}, S L D R=0.5 \mathrm{day}^{-1}$, and $S L R O=66$.

Based on the particle size distribution and soil bulk density data in Table 1, two soil layers $0-15 \mathrm{~cm}$ and $15-180 \mathrm{~cm}$ were distinguished for the experimental field at UF, Gainesville, consisting of sand and loamy sand, respectively. Parameters for the van Genuchten-Mualem soil water retention functions (van Genuchten, 1980) for these two soil textures were taken from the HYDRUS-1D soil catalog and then used in the DSSATHYDRUS-1D coupled model (Table 2).

The soil of the second experimental field at ISU was characterized as Nicollet clay loam (fine-loamy, mixed, Mesic Aquic). This soil profile in the DSSAT soil dataset was identified as IBSB910049. Since the IBSB910049 soil profile contains only data necessary to run DSSAT, while lacking data on soil texture and the saturated hydraulic conductivity, we assumed that the entire soil profile was homogeneous and used the HYDRUS-1D default parameters for a clay loam soil (Table 2).

The soybean varieties "BRAGG" and "Williams-82" were used in the field experiments at UF and ISU, respectively. Their default cultivar coefficients are given in the soybean cultivar file SBGRO046.CUL in DSSAT. The cultivar coefficients for BRAGG are shown in Table 3 . The peanut experiments were carried out using the variety "Florunner". Its cultivar-specific parameters as used in the DSSAT CSM and coupled DSSATHYDRUS-1D simulations are also listed in Table 3. Several parameters of the soybean and peanut varieties had been calibrated earlier for the DSSAT CSM simulations. Specifically, the BRAGG and Florunner cultivar coefficients were taken from the standard DSSAT V4.6 release, as previously calibrated for DSSAT V4.6 based on a full set of 7 and 18 treatments, respectively. The peanut variety Florunner was calibrated for the coupled DSSAT-HYDRUS-1D model using data from the field experiment conducted at UF in 1989. Modified values of several cultivar coefficients of this variety for the coupled model are given in Table 3, together with those used for DSSAT CSM.

The datasets, distributed with DSSAT V4.6 and used for evaluation of the coupled model, were from a) soybean experiments UFGA7801 (1978, treatment 1, irrigated, $206 \mathrm{~mm}$ in 21 applications, and treatment 2, rainfed), IUAM8801 (1988, treatment 1, rainfed) and IUAM9001 (1990, treatment 1, rainfed), and b) peanut experiments UFGA8401 (1984, treatment 1 , irrigated, $365 \mathrm{~mm}$ in 16 applications, and treatment 2, rainfed, except irrigation, $243 \mathrm{~mm}$ in 9 applications, after water deficit period was relieved), UFGA8601 (1986, treatment 1, rainfed), and UFGA8701 (1987, treatment 1, irrigated, 115 $\mathrm{mm}$ in 8 applications). The names of the experiments follow the DSSAT file name convention and are constructed from 8 characters that include an institute code ( 2 characters), a site code ( 2 characters), the year of the experiment ( 2 characters), and an experiment number ( 2 characters). For example, UFGA7801 is an experiment (01) conducted by the University of Florida (UF) at Gainesville (GA) in 1978 (78) and IUAM8801 is an experiment (01) conducted by the Iowa State University (IU) at Ames (AM) in 1988 (88). Available measurements included total crop mass, leaf mass, stem mass, pod mass, grain mass, leaf area index $(L A I)$, the V-stage (leaf number on main axis), specific leaf area, leaf nitrogen concentration, grain number, unit grain mass, pod number, shelling \% and dates for anthesis, first pod, first seed, and physiological maturity.

Table 1. Soil physical and hydraulic properties of the experimental field at the University of Florida, Gainesville.

\begin{tabular}{|c|c|c|c|c|c|c|c|c|c|c|}
\hline \multirow{2}{*}{$\begin{array}{l}\text { Depth } \\
\mathrm{cm} \\
\end{array}$} & \multicolumn{3}{|c|}{ Particle size distribution, $\%$} & \multirow{2}{*}{$\begin{array}{c}\begin{array}{c}\text { Bulk } \\
\text { density }\end{array} \\
\mathrm{g} \mathrm{cm}^{-3}\end{array}$} & \multirow{2}{*}{$\begin{array}{c}\text { Lower } \\
\text { limit } \\
\mathrm{cm}^{3} \mathrm{~cm}^{-3}\end{array}$} & \multirow{2}{*}{$\begin{array}{c}\text { Upper } \\
\text { limit, } \\
\text { drained } \\
\mathrm{cm}^{3} \mathrm{~cm}^{-3}\end{array}$} & \multirow{2}{*}{$\begin{array}{c}\text { Upper } \\
\text { limit, } \\
\text { saturated } \\
\mathrm{cm}^{3} \mathrm{~cm}^{-3} \\
\end{array}$} & \multirow{2}{*}{$\begin{array}{c}\begin{array}{c}\text { Saturated } \\
\text { hydraulic } \\
\text { conductivity }\end{array} \\
\mathrm{cm} \mathrm{h}^{-1}\end{array}$} & \multirow{2}{*}{$\begin{array}{c}\begin{array}{c}\text { Organic } \\
\text { carbon }\end{array} \\
\%\end{array}$} & \multirow{2}{*}{$\begin{array}{l}\text { Root } \\
\text { growth } \\
\text { factor }\end{array}$} \\
\hline & clay & silt & sand & & & & & & & \\
\hline $0-5$ & 0.9 & 11.8 & 87.3 & 1.36 & 0.023 & 0.086 & 0.230 & 7.40 & 0.9 & 1.00 \\
\hline $5-15$ & 0.9 & 11.8 & 87.3 & 1.40 & 0.023 & 0.086 & 0.230 & 7.40 & 0.69 & 1.00 \\
\hline $15-30$ & 4.6 & 6.4 & 89 & 1.46 & 0.023 & 0.086 & 0.230 & 15.80 & 0.28 & 0.55 \\
\hline $30-45$ & 5.8 & 5.4 & 88.8 & 1.46 & 0.023 & 0.086 & 0.230 & 28.00 & 0.20 & 0.32 \\
\hline $45-60$ & 5.8 & 5.4 & 88.8 & 1.47 & 0.023 & 0.086 & 0.230 & 28.00 & 0.20 & 0.32 \\
\hline $60-90$ & 9.6 & 4.2 & 86.2 & 1.43 & 0.021 & 0.076 & 0.230 & 27.60 & 0.09 & 0.38 \\
\hline $90-120$ & 9.6 & 4.2 & 86.2 & 1.48 & 0.020 & 0.076 & 0.230 & 17.50 & 0.03 & 0.40 \\
\hline $120-150$ & 8.3 & 3.6 & 88.1 & 1.57 & 0.027 & 0.13 & 0.230 & 0.30 & 0.03 & 0.30 \\
\hline $150-180$ & 8.3 & 3.6 & 88.1 & 1.79 & 0.070 & 0.258 & 0.360 & 0.10 & 0.03 & 0.20 \\
\hline
\end{tabular}

Table 2. Values of the van Genuchten-Mualem soil hydraulic parameters as obtained from the HYDRUS-1D Soil Catalog (Carsel and Parrish, 1988) for two experimental fields soils $\left(\theta_{r}\right.$ is the residual water content, $\theta_{s}$ is the saturated water content, $\alpha, n$, and $l$ are empirical parameters, and $K_{s}$ is the saturated soil hydraulic conductivity).

\begin{tabular}{|c|c|c|c|c|c|c|c|c|}
\hline Soil ID & $\begin{array}{c}\text { Depth } \\
\mathrm{cm}\end{array}$ & Soil type by texture & $\begin{array}{c}\theta_{r} \\
\mathrm{~cm}^{3} / \mathrm{cm}^{3}\end{array}$ & $\begin{array}{c}\theta_{s} \\
\mathrm{~cm}^{3} / \mathrm{cm}^{3}\end{array}$ & $\begin{array}{c}\alpha \\
1 / \mathrm{cm} \\
\end{array}$ & $n$ & $l$ & $\begin{array}{c}K_{s} \\
\mathrm{~m} / \text { day }\end{array}$ \\
\hline IBPN910015,IBSB910015 & $0-15$ & Fine sand & 0.045 & 0.43 & 0.145 & 2.68 & 0.5 & 7.13 \\
\hline IBPN910015, IBSB910015 & $15-180$ & Loamy fine sand & 0.057 & 0.41 & 0.124 & 2.28 & 0.5 & 3.50 \\
\hline IBSB910049 & $0-202$ & Clay loam & 0.079 & 0.442 & 0.016 & 1.414 & 0.5 & 0.082 \\
\hline
\end{tabular}


Table 3. Cultivar coefficients for the soybean variety BRAGG (SB) and the peanut variety Florunner (PN) used in the DSSAT-CSM and the coupled DSSAT-HYDRUS-1D simulations.

\begin{tabular}{|c|c|c|c|c|c|c|c|c|c|}
\hline \# & Coeff. & SB & PN & Definitions & \# & Coeff. & SB & PN & Definitions \\
\hline 1 & CSDL & 12.33 & 11.84 & Critical short-day length, hour & 10 & SIZLF & 170 & 18.0 & $\begin{array}{l}\text { Maximum size of full leaf (three } \\
\text { leaflets), } \mathrm{cm}^{2}\end{array}$ \\
\hline 2 & PPSEN & 0.32 & 0.00 & $\begin{array}{l}\text { Slope of the relative response of } \\
\text { development to photoperiod with } \\
\text { time, } 1 / \text { hour }\end{array}$ & 11 & XFRT & 1.0 & 0.92 & $\begin{array}{l}\text { Maximum fraction of daily } \\
\text { growth that is partitioned to seed } \\
+ \text { shell }\end{array}$ \\
\hline 3 & EM-FL & 19.5 & $\begin{array}{l}21.2 \\
20.2\end{array}$ & $\begin{array}{l}\text { Time between plant emergence } \\
\text { and flower appearance (R1), } \\
\text { photothermal days }\end{array}$ & 12 & WTPSD & 0.17 & $\begin{array}{c}0.69, \\
0.65\end{array}$ & Maximum weight per seed, $g$ \\
\hline 4 & FL-SH & 10.0 & $\begin{array}{l}9.2, \\
8.2\end{array}$ & $\begin{array}{l}\text { Time between first flower and } \\
\text { first pod (R3), photothermal days }\end{array}$ & 13 & SFDUR & 24 & 40 & $\begin{array}{l}\text { Seed filling duration for pod } \\
\text { cohort at standard growth condi- } \\
\text { tions, photothermal days }\end{array}$ \\
\hline 5 & FL-SD & 15.2 & $\begin{array}{l}18.8, \\
24.8\end{array}$ & $\begin{array}{l}\text { Time between first flower and } \\
\text { first seed (R5), photothermal } \\
\text { days }\end{array}$ & 14 & SDPDV & 2 & $\begin{array}{l}1.65, \\
1.6\end{array}$ & $\begin{array}{l}\text { Average seed per pod under } \\
\text { standard growing conditions, } \\
\text { \#/pod }\end{array}$ \\
\hline 6 & SD-PM & 37.6 & $\begin{array}{l}74.3, \\
77.3\end{array}$ & $\begin{array}{l}\text { Time between first seed (R5) and } \\
\text { physiological maturity (R7), } \\
\text { photothermal days }\end{array}$ & 15 & PODUR & 10 & $\begin{array}{l}24, \\
26\end{array}$ & $\begin{array}{l}\text { Time required for cultivar to reach } \\
\text { final pod load under optimal } \\
\text { conditions, photothermal days }\end{array}$ \\
\hline 7 & FL-LF & 19 & $\begin{array}{c}88, \\
90\end{array}$ & $\begin{array}{l}\text { Time between first flower (R1) } \\
\text { and end of leaf expansion, } \\
\text { photothermal days }\end{array}$ & 16 & THRSH & 78 & 80 & $\begin{array}{l}\text { Maximum ratio of } \\
\text { (seed/(seed+shell)) at maturity, } \\
\text { Threshing percentage }\end{array}$ \\
\hline 8 & LFMAX & 1.0 & 1.4 & $\begin{array}{l}\text { Maximum leaf photosynthesis } \\
\text { rate at } 30^{\circ} \mathrm{C}, 350 \mathrm{vpm} \mathrm{CO} \mathrm{CO}_{2} \text {, and } \\
\text { high light, } \mathrm{mg} \mathrm{CO} \mathrm{CO}_{2}{ }^{2} \mathrm{~s}\end{array}$ & 17 & SDPRO & 0.40 & 0.27 & $\begin{array}{l}\text { Fraction protein in seeds, } \\
\mathrm{g}(\text { protein }) / \mathrm{g}(\text { seed })\end{array}$ \\
\hline 9 & SLAVR & 355 & $\begin{array}{l}260, \\
264\end{array}$ & $\begin{array}{l}\text { Specific leaf area of cultivar } \\
\text { under standard growth condi- } \\
\text { tions }, \mathrm{cm}^{2} / \mathrm{g}\end{array}$ & 18 & SDLIP & 0.20 & 0.51 & $\begin{array}{l}\text { Fraction oil in seeds, } \\
\mathrm{g}(\text { oil }) / \mathrm{g}(\text { seed })\end{array}$ \\
\hline
\end{tabular}

The numerical time steps of HYDRUS-1D in the coupled model varied between $10^{-3}$ and 1 day, while the time step in DSSAT CSM was always 1 day. The soil profile in HYDRUS1D was discretized into $1-\mathrm{cm}$ soil layers in the top $30 \mathrm{~cm}, 2-\mathrm{cm}$ soil layers down to a depth of $150 \mathrm{~cm}$, and $3-\mathrm{cm}$ soil layers until a depth of 180 or $202 \mathrm{~cm}$.

\section{Statistical indicators}

Several statistical indicators were used to compare the performance of the original and coupled models and their capability to describe the experimental data. The indicators included the Mean, the Root Mean Square Error (RMSE), the normalized Root Mean Square Error (nRMSE) (Loague and Green, 1991), the index of agreement $(d)$ (Willmott et al., 1985), the Model Efficiency $(E F)$ (Nash and Sutcliffe, 1970), and the Mean Error (E).

The RMSE was computed using

$R M S E=\sqrt{\frac{\sum_{i=1}^{n}\left(P_{i}-O_{i}\right)^{2}}{n}}$

where $P_{i}$ and $O_{i}$ are the simulated and observed values for the $i$ th measurement, respectively, and $n$ is the number of observations.

The $n R M S E$ was computed as:

$n R M S E=\frac{R M S E}{\bar{O}} \times 100 \%$

where $\bar{O}$ is the overall mean of observed values.

The $d$ index was calculated using the equation:

$$
d=1-\frac{\sum_{i=1}^{n}\left(P_{i}-O_{i}\right)^{2}}{\sum_{i=1}^{n}\left(\left|P_{i}-\bar{O}\right|+\left|O_{i}-\bar{O}\right|\right)^{2}}
$$

while the Model Efficiency $(E F)$ was computed using

$$
E F=1-\frac{\sum_{i=1}^{n}\left(P_{i}-O_{i}\right)^{2}}{\sum_{i=1}^{n}\left(\left|O_{i}-\bar{O}\right|\right)^{2}}
$$

and the Mean Error $(E)$ as

$$
E=\frac{\sum_{i=1}^{n}\left(P_{i}-O_{i}\right)}{n}
$$

A high value of the $d$ index $(0 \leq d \leq 1)$ and a low value of $R M S E$ indicate a good fit between the simulated and observed values. Since $E F$ has no unit, this criterion can be used to compare the accuracy of model outputs for different variables. Its value can range from $-\infty$ to 1 . The closer the model efficiency is to 1, the more accurate the model, with $E F=1$ corresponding to a perfect match between simulated values and observed data. A value of zero for the efficiency $E$ indicates that the predictions are as accurate as the mean of the observed data, whereas an efficiency less than zero suggests that the observed mean is a better predictor than the model. $E$ is an indicator of whether the model predictions tend to underestimate (if negative) or overestimate (if positive) the measured data.

\section{RESULTS AND DISCUSSION}

The two approaches for soil water modeling in DSSAT were evaluated based on their ability to accurately estimate the soil water balance, the soil water content by soil layer, potential and actual evapotranspiration rates and, subsequently, crop growth, which was characterized using both total and individual organ biomass accumulation. 


\section{Soil water balance}

Since coupling added new functionality to the soil water simulations in DSSAT, the performance of the original and coupled models was evaluated first in terms of their ability to predict soil water contents (total and extractable) in the entire soil profile and particular soil layers during the crop growing season. Both irrigated or rainfed treatments were considered in the analysis.

For the UFGA7801 soybean experiment, the initial total water content in the soil profile $180 \mathrm{~cm}$ deep was $214 \mathrm{~mm}$ (equivalent to field Capacity in DSSAT-CSM) for both treatments (treatment 1 was irrigated and treatment 2 was rainfed). Simulations with both models showed a similar tendency of describing the dynamics of the total soil water content (SWTD) (Fig. 2a,b). Similar simulated trends can also be seen for extractable amount of soil water ( $S W X D)$ (Fig. 2c,d). The extractable soil water as obtained with the coupled model was in general higher than when simulated with the original model. For example, one can see that the SWXDs simulated using both models were higher than those measured in treatment 2 of the 1978 soybean experiment (Fig. 2d). Values of the $d$ index were 0.95 and 0.90 and those of RMSE were $26.5 \mathrm{~mm}$ and $41.3 \mathrm{~mm}$ for the original and coupled models, respectively.

The soybean experiments at Ames, Iowa in 1988 and 1990 included data about the Williams-82 soybean variety grown under rainfed conditions. The 1988 season showed a major drought, which allowed us to contrast its results with the cool and rainy season of 1990. Soil water contents during the 1988 experiment were measured with a neutron probe. Initial conditions and water content distributions with depth were different in the 202-cm deep soil profile for these soybean experiments. For treatment 1 of the IUAM8801 experiment and treatment 1 of the IUAM9001 experiment, the total water contents (SWTD) were $628 \mathrm{~mm}$ and $574 \mathrm{~mm}$, respectively, with water contents in different layers being close to the drained upper limit.

Simulations by both models showed a similar tendency of describing soil water content dynamics for the Iowa experiments (Fig. 3). On 103 DAP (days after planting) of the 1988 growing season, a large 142-mm rainfall event occurred (Fig. $3 a)$. The original and coupled models reacted from this by increasing the total water content by $80 \mathrm{~mm}$ and $136 \mathrm{~mm}$, respectively (Fig. 3a). While the tipping bucket approach limited infiltration as determined by the SCS curve number, the water content of the near-surface soil layer, and the total soil drainage coefficient (SWCON) (see Table 2), the HYDRUS-1D approach, which considers not only gravity but also capillarity, allowed larger infiltration. Both modeling approaches produced similar results for the cool and rainy season of 1990, while the coupled model slightly overpredicted water contents during most of the season (Fig. 3b,d).

Comparisons between volumetric water contents measured in the different layers during the 1988 soybean experiment and simulated using the DSSAT CSM and the DSSAT-HYDRUS1D models are illustrated in Fig. 4. In most cases, the $d$ index was approximately 0.9 for the original model and 0.8 for the coupled model. The RMSE values for the original and coupled models were 0.08 and 0.05 , respectively. The coupled model simulated more soil water depletion in the deeper layers during the early part of the season. The two modeling approaches again showed different responses to a large rainfall amount (142 mm) on 103 DAP. The original model failed to re-saturate the soil profile because of excessively high runoff caused by incorrect application of the SCS runoff number to a cracking clay soil, while the coupled model simulated a much large increase in the total water content on day 103 due to better simulations of infiltration.

The initial total water content $(214 \mathrm{~mm})$ of the $180-\mathrm{cm}$ deep soil profile, and the water contents at depths of 5, 15, 30, 45, $60,90,120,150$, and $180 \mathrm{~cm}$, were the same in all three peanut (UFGA8401, UFGA8601, and UFGA8701) experiments at Gainesville, FL when the simulations started on 19, 5, and 2 days before planting, respectively. The coupled model showed lower water contents at the beginning of all simulations through about 40-50 days after planting (DAP) in both treatments of the UFGA8401 experiment (Fig. 5a,b). This was expected for sandy soils that have very low water retention properties.

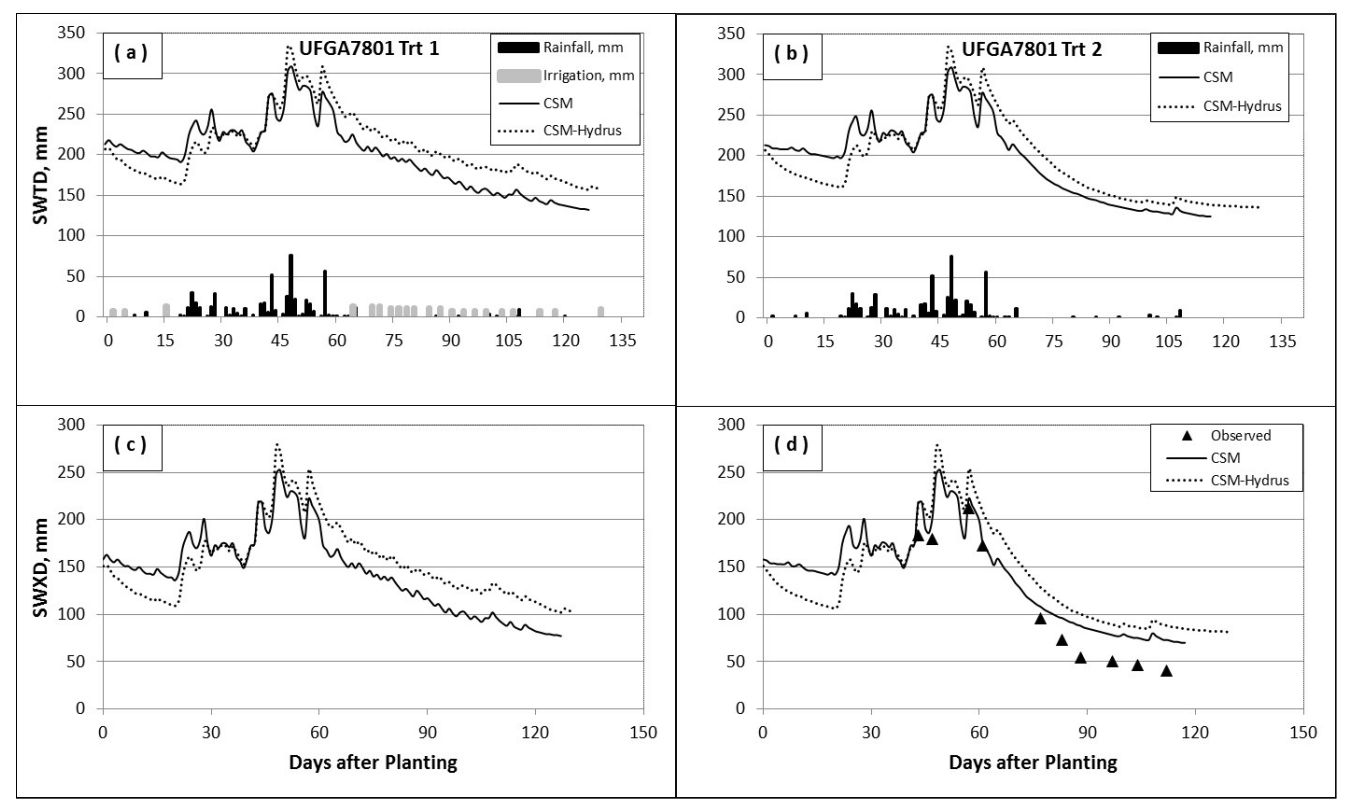

Fig. 2. Total water contents $(S W T D)(\mathrm{a}, \mathrm{b})$ and extractable water contents $(S W X D)(\mathrm{c}, \mathrm{d})$ in the $0-180 \mathrm{~cm}$ soil profile as simulated with the DSSAT CSM and DSSAT-HYDRUS-1D models for an irrigated treatment 1 (left) and rainfed treatment 2 (right). Also shown are measured total plant extractable soil water (d) and irrigation and rainfall amounts $(a, b)$ during the BRAGG soybean growing season at Gainesville, FL, in 1978. 


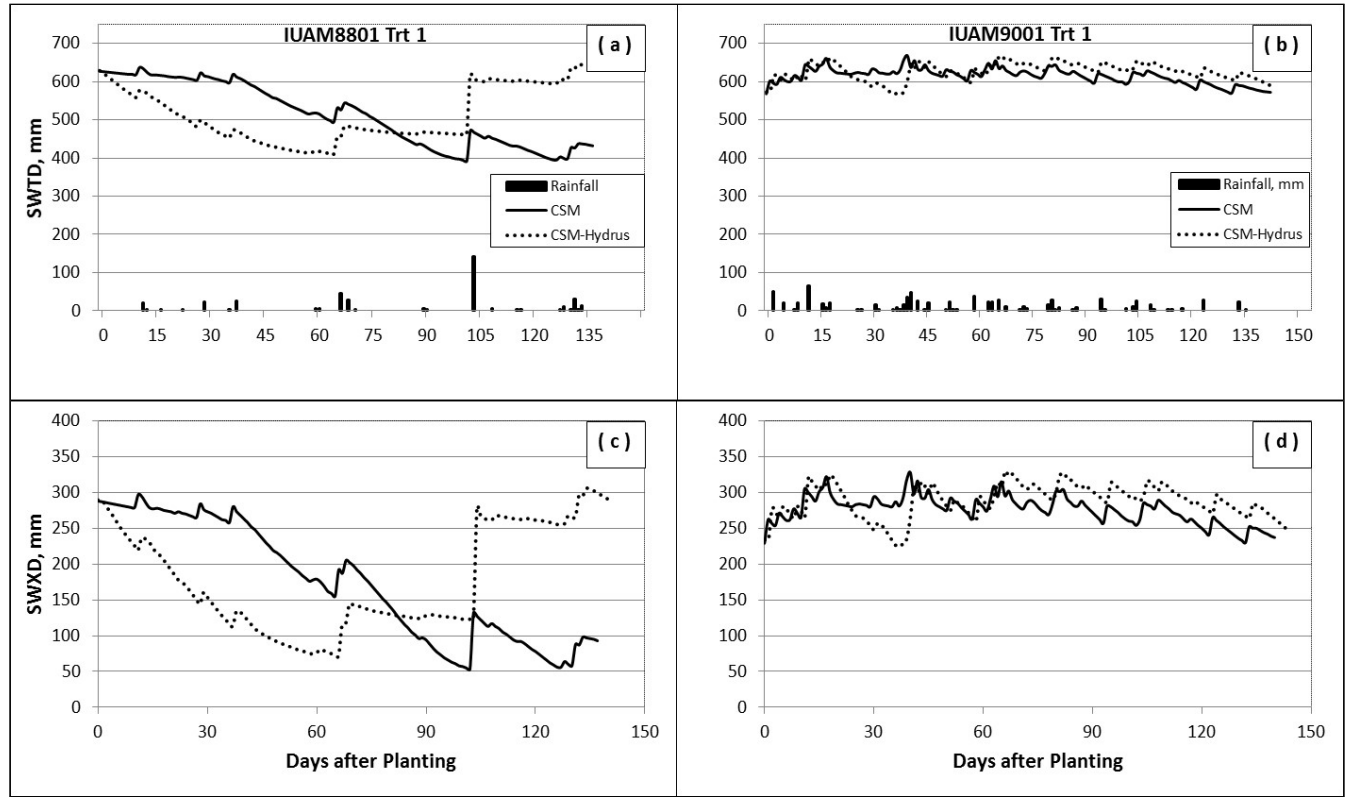

Fig. 3. Total water contents $(S W T D)(\mathrm{a}, \mathrm{b})$ and extractable water contents $(S W X D)(\mathrm{c}, \mathrm{d})$ in the $0-202 \mathrm{~cm}$ soil profile as simulated with the DSSAT CSM and DSSAT-HYDRUS-1D models for 1988 (left) and 1990 (right). Also shown are rainfall amounts during the Williams-82 soybean growing season at Ames, IA, in 1988 (a) and 1990 (b).

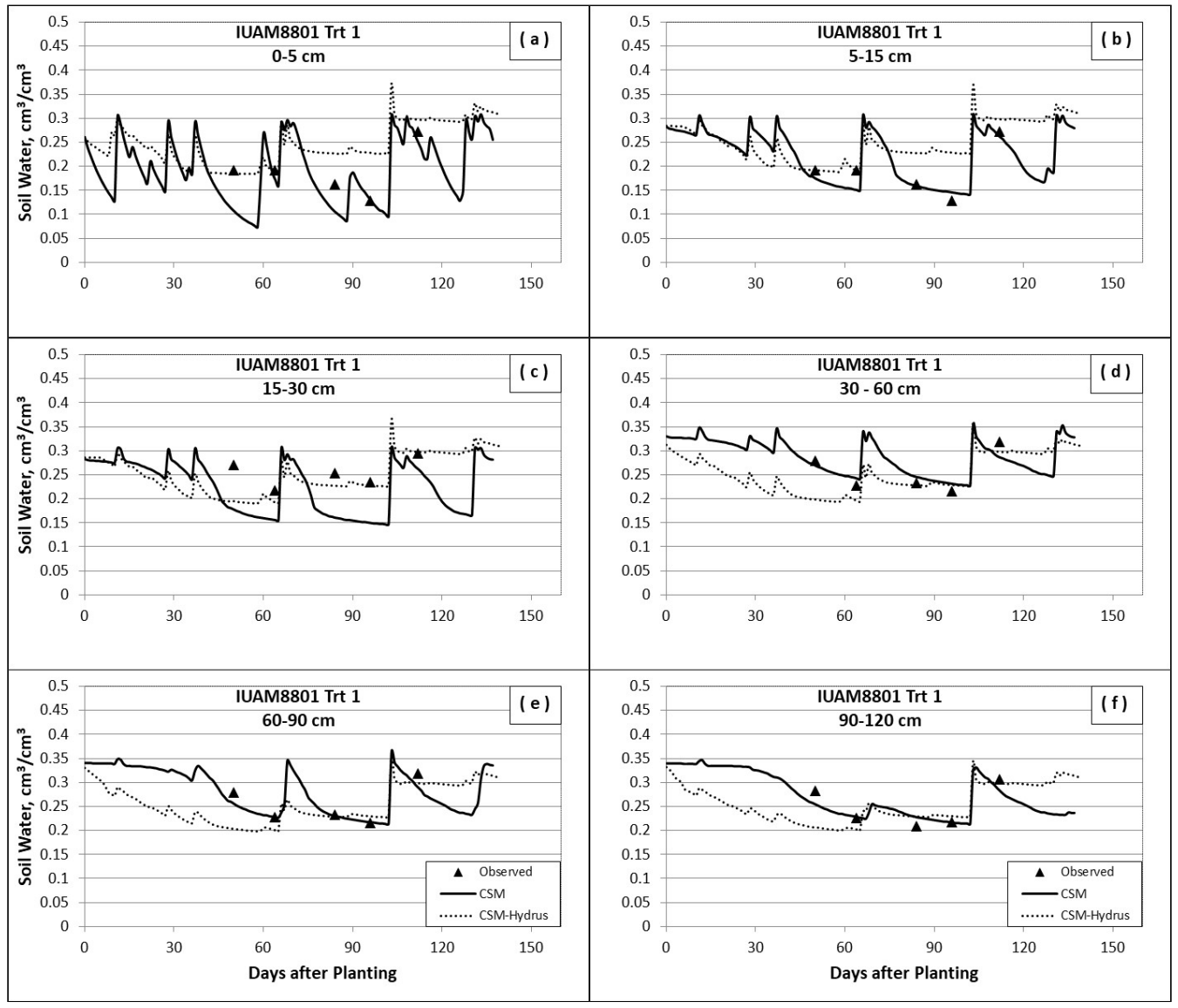

Fig. 4. Measured and simulated water contents of six soil layers as simulated with the DSSAT CSM and DSSAT-HYDRUS-1D models during the Williams-82 soybean growing season at Ames, IA, in 1988.

After this initial period, water contents simulated with the coupled model were slightly higher than those simulated with the original model. The two models adequately reacted to precipitation and showed similar water content dynamics, albeit at different levels (Fig. 5).

\section{Daily and seasonal evapotranspiration}

The performance of the two models was also evaluated in terms of their ability to predict potential and actual evapotranspiration rates. Potential evapotranspiration dynamics and their values were the same for both models (Figs. 6a,b and 7a,b). 


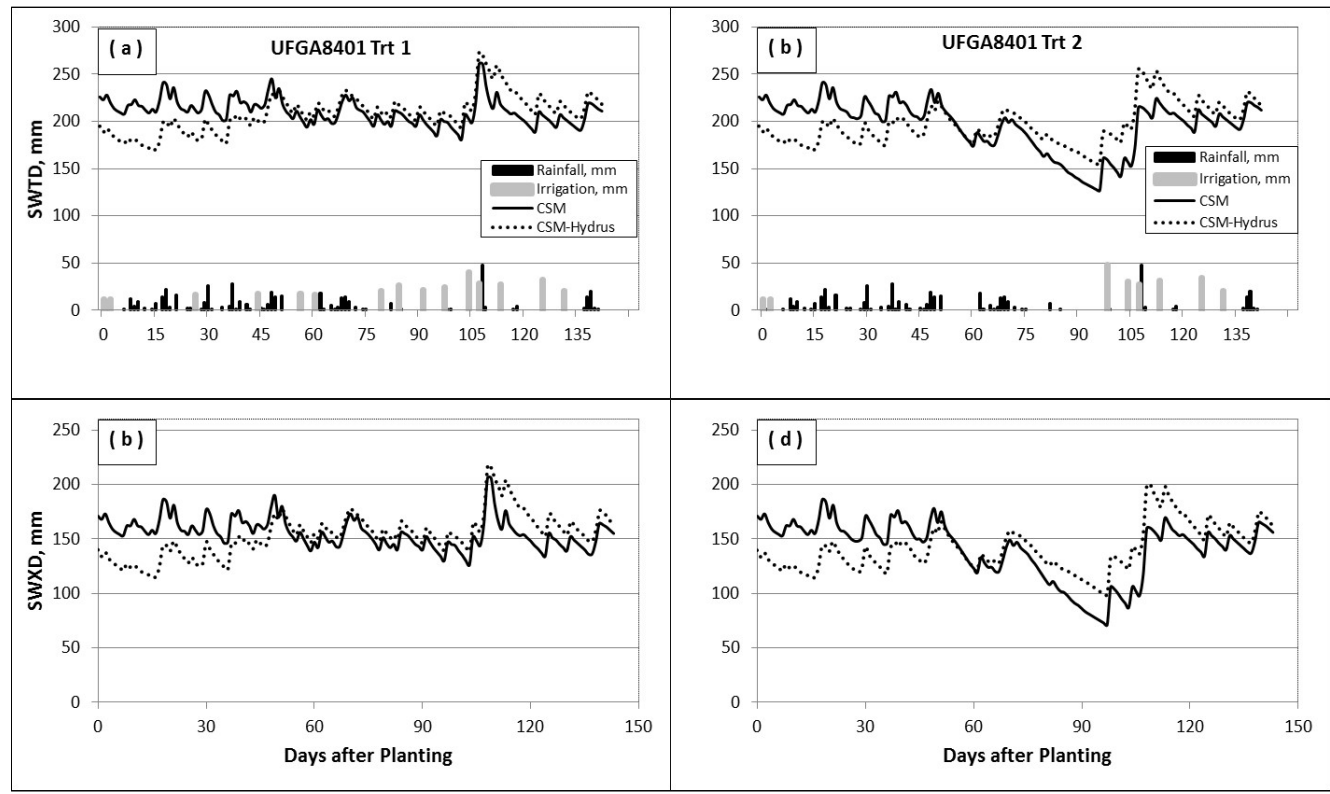

Fig. 5. Total water contents $(S W T D)(\mathrm{a}, \mathrm{b})$ and extractable water contents $(S W X D)(\mathrm{c}, \mathrm{d})$ as simulated with the DSSAT CSM and DSSATHYDRUS-1D models for treatments 1 (left) and 2 (right). Also shown are rainfall and irrigation amounts for the two treatments of the Florunner peanut experiment at Gainesville, FL in 1984 (a,b).

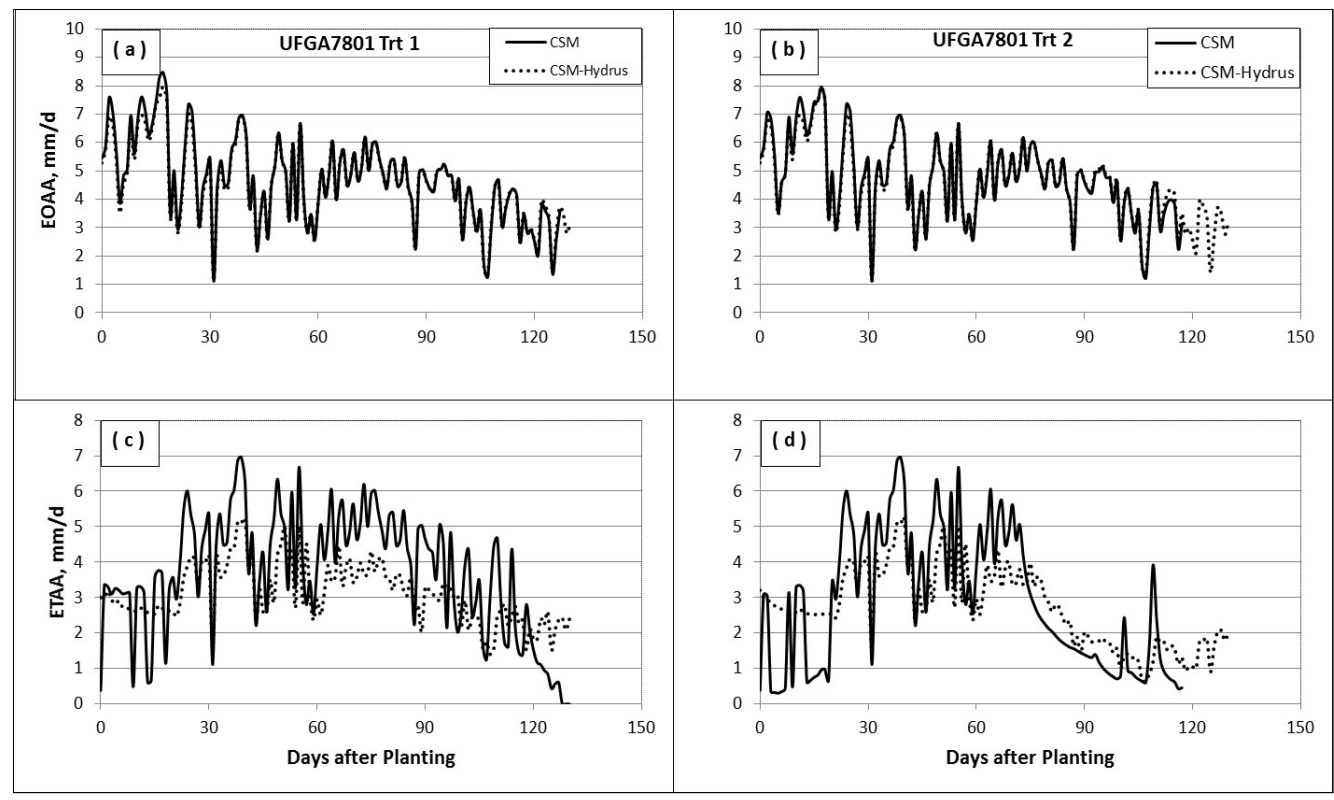

Fig. 6. Potential evapotranspiration $(E O A A)(\mathrm{a}, \mathrm{b})$ and actual evapotranspiration $(E T A A)(\mathrm{c}, \mathrm{d})$ rates as simulated with the DSSAT CSM and the DSSAT-HYDRUS-1D models for Treatment 1 (left, irrigated) and Treatment 2 (right, rainfed) of the BRAGG soybean experiment at Gainesville, FL, in 1978.

Actual evapotranspiration rates differed significantly between the two models. The coupled model showed less variations in its predictions, although the trend was similar compared to the original model (Figs. 6c,d and 7c,d). For both UFGA7801 soybean treatments during full canopy, evapotranspiration values varied between $2.5-5 \mathrm{~mm} /$ day and $3-7 \mathrm{~mm}$ /day for the coupled and the original models, respectively.

The coupled and original models produced comparable values for the evapotranspiration rate at the beginning of the growing season (about $3 \mathrm{~mm}$ and $3.5 \mathrm{~mm}$, respectively) and at the end of the season (1.5-2.5 $\mathrm{mm}$ and 1-3 $\mathrm{mm}$, respectively), for irrigated treatment 1 (Fig. 6c). Differences were more significant in the case of the treatment 2 (rainfed): about $2.5 \mathrm{~mm}$ and $0.5-1 \mathrm{~mm}$ at the beginning of the season and 1-2 $\mathrm{mm}$ and
$0.5-1 \mathrm{~mm}$ at the end of the season for the coupled and original models, respectively (Fig. 6d). However, the seasonal patterns of the coupled model differed from the original CSM. The coupled model had higher evapotranspiration (ETAA) rates during the early season when $L A I$ values were still low, but lower ETAA rates in mid-season with its higher $L A I$ values.

DSSAT CSM results showed differences in the average daily evapotranspiration rates between for the irrigated and rainfed treatments of the UFGA8401 peanut experiment (Fig. $7 \mathrm{c}, \mathrm{d}$ ), for only 24 out of 143 days of simulations, with differences that varied between $1.4-3 \mathrm{~mm} /$ day. The coupled model showed differences in evapotranspiration between the two treatments during 80 days of the 143 simulation days, with maximum differences of about $2 \mathrm{~mm}$ (Fig. 7c,d). By comparison, 


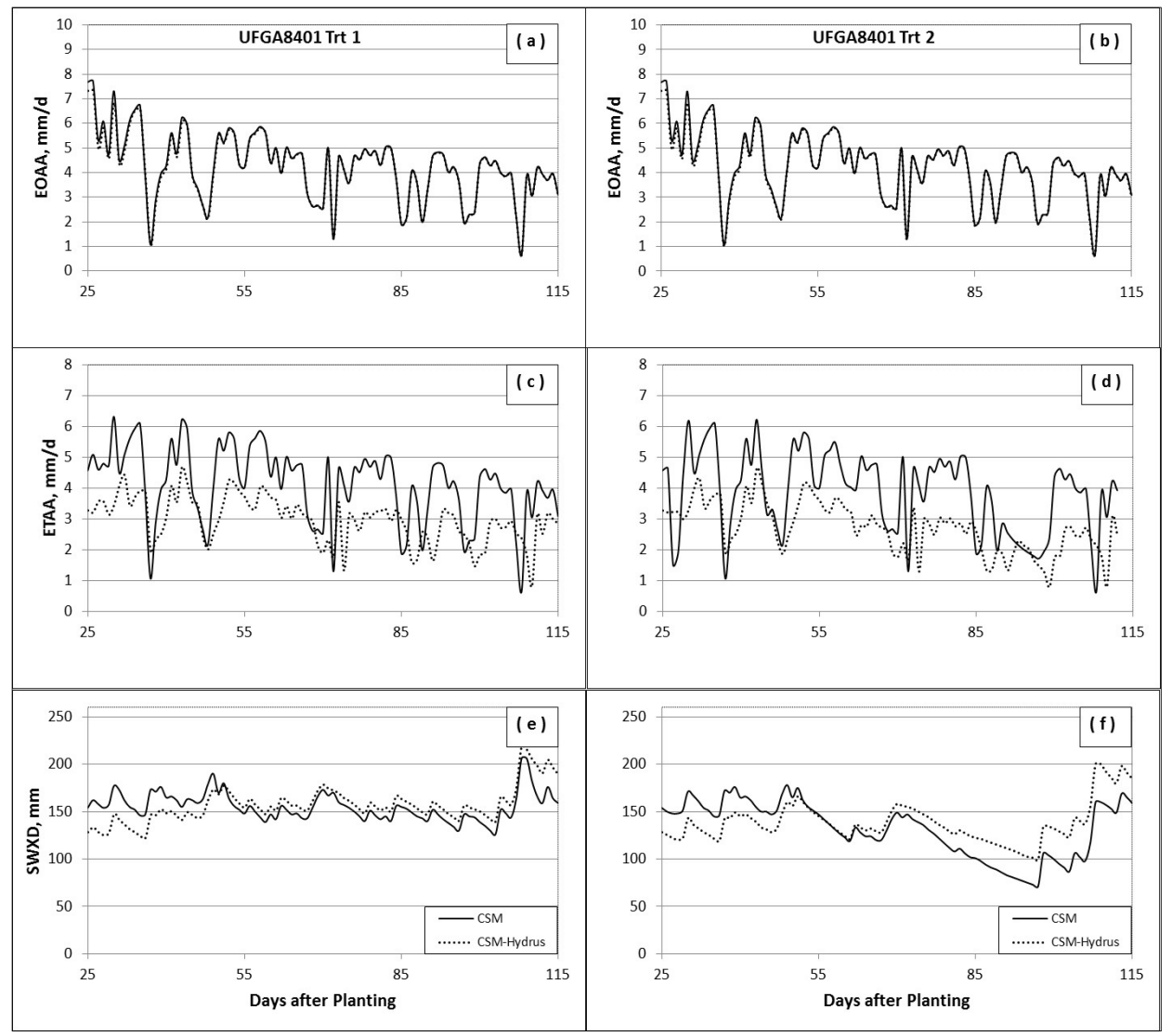

Fig. 7. Potential $(E O A A)(\mathrm{a}, \mathrm{b})$ and actual $(E T A A)(\mathrm{c}, \mathrm{d})$ evapotranspiration rates and extractable soil water $(S W X D)(\mathrm{e}, \mathrm{f})$ as simulated with the DSSAT CSM and the DSSAT-HYDRUS-1D models for Treatment 1 (left, irrigated) and Treatment 2 (right, rainfed) of the Florunner peanut experiment at Gainesville, FL, in 1984.

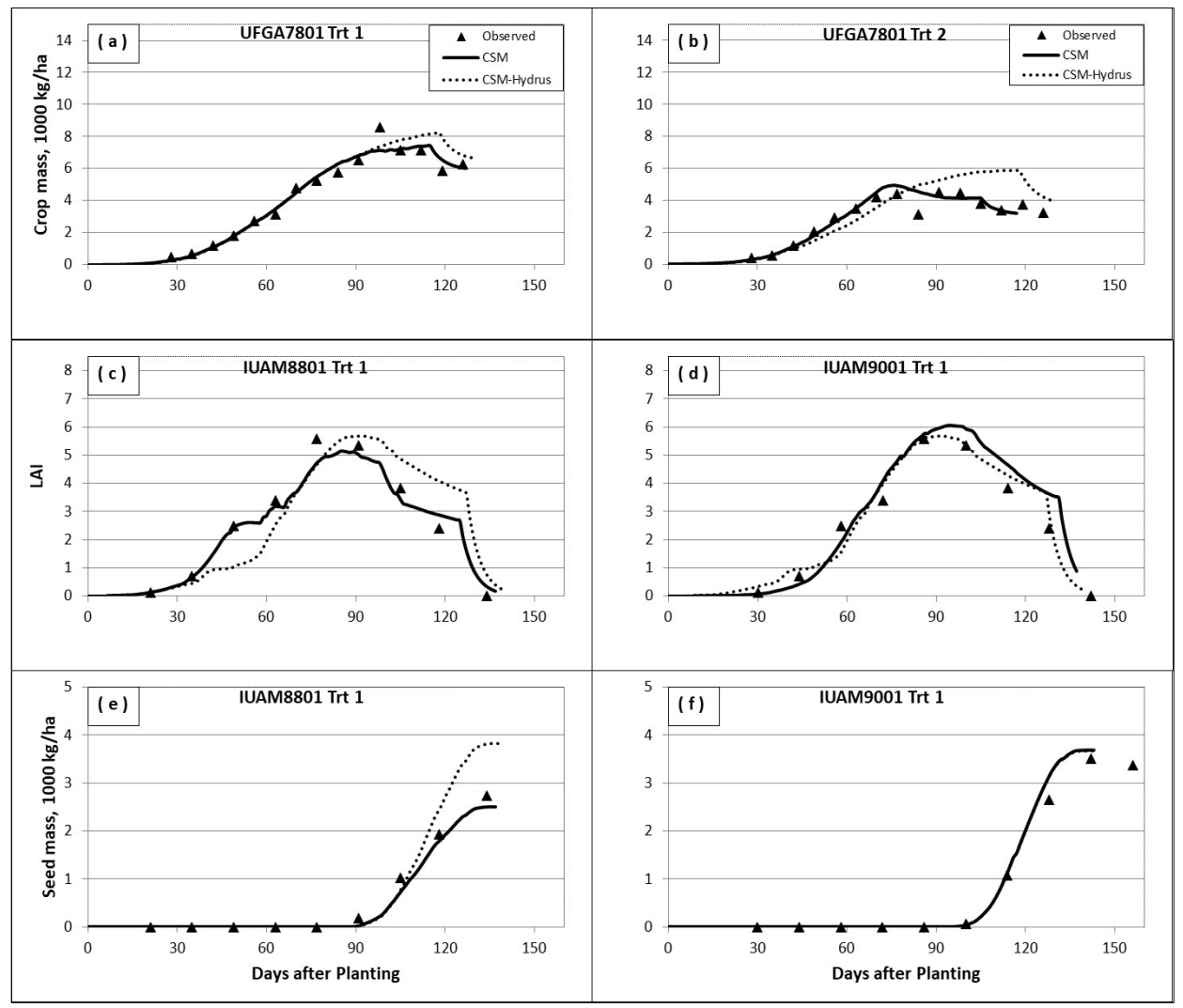

Fig. 8. Simulated and observed crop mass for the BRAGG (a,b) soybean experiments at Gainesville, FL in 1978 , and $L A I$ s and seed mass for the Williams 82 (c-f) soybean experiments at Ames, IA in 1988 and 1990, respectively. Simulations were carried out using the DSSAT CSM model with its tipping bucket approach and the coupled DSSAT-HYDRUS-1D model. 
the original model did not show any differences for the two treatments after 98 DAP, although $48 \mathrm{~mm}$ irrigation was applied on day 98 after planting and $139 \mathrm{~mm}$ during the period of 98-114 DAP, while the coupled model simulated more evapotranspiration for irrigated treatment 1 until 115 DAP.

Fig. 7 shows results obtained with the two modeling approaches for the time interval of 25-115 DAP out of 0-143 DAP when differences were found between the irrigated and rainfed treatments. Similarly as for the soybean example, the coupled model tended to produce lower values than the CSM approach during much of the season.

\section{Crop growth simulations}

The comparison between simulated and observed yield components during the growing season indicated the different per- formance of the DSSAT-HYDRUS-1D and original CSM models. Of the three soybean experiments, the coupled model performed worst for treatment 2 of the UFGA7801 experiment, which showed a very low value of the $d$ index (0.47) for pod mass, compared to 0.91 for the original model (Table 4).

The $E F$ values were negative for this treatment as well. The original and coupled models performed well for treatment 1 , producing relatively high values (0.99) of the $d$ index for pod and stem mass, and with slightly better $d$ index values for the original model for crop mass and LAI (0.99 and 0.95, respectively) than the coupled model (0.98 and 0.95 , respectively). The coupled model performed better for the IUAM9001 experiment (Table 4, Fig. 8d,f) in terms of all statistical measures than for the IUAM8801 soybean experiment (Table 4, Fig. 8c,e).

Table 4. Comparisons of observed and simulated crop mass, pod mass, stem mass, and LAI using the original DSSAT CSM model (CSM) and the coupled DSSAT-HYDRUS-1D model (HYD) for three soybean experiments and their statistical indicators.

\begin{tabular}{|c|c|c|c|c|c|c|c|c|c|c|c|c|c|c|}
\hline \multirow[b]{2}{*}{ Biomass component } & \multirow[b]{2}{*}{ Trt \# } & \multirow[b]{2}{*}{ Mean (Obs.) } & \multicolumn{2}{|c|}{ Mean (Sim.) } & \multicolumn{2}{|c|}{ RMSE } & \multicolumn{2}{|c|}{$n R M S E$} & \multicolumn{2}{|c|}{$d$} & \multicolumn{2}{|c|}{$E F$} & \multicolumn{2}{|c|}{$E$} \\
\hline & & & CSM & HYD & CSM & HYD & CSM & HYD & $\mathrm{CSM}$ & HYD & $\mathrm{CSM}$ & HYD & CSM & HYD \\
\hline \multicolumn{15}{|c|}{ UFGA7801 } \\
\hline Crop mass, $\mathrm{kg} / \mathrm{ha}$ & 1 & 4485 & 4501 & 4722 & 478 & 731 & 10.7 & 16.3 & 0.99 & 0.98 & 0.96 & 0.83 & 16 & 236 \\
\hline Pod mass, kg/ha & 1 & 2336 & 2280 & 2514 & 227 & 317 & 9.7 & 13.6 & 0.99 & 0.99 & 0.98 & 0.94 & -56 & 178 \\
\hline Stem mass, kg/ha & 1 & 2069 & 2099 & 2107 & 220 & 273 & 10.6 & 13.2 & 0.99 & 0.99 & 0.96 & 0.96 & 30.87 & 38.6 \\
\hline LAI & 1 & 2.85 & 2.89 & 3.1 & 0.4 & 0.6 & 14.3 & 22.6 & 0.98 & 0.95 & 0.93 & 0.92 & 0.04 & 0.22 \\
\hline Crop mass, kg/ha & 2 & 2960 & 3054 & 3541 & 468 & 1191 & 15.8 & 39.3 & 0.97 & 0.86 & 0.89 & 0.20 & 94.3 & 510 \\
\hline Pod mass, kg/ha & 2 & 655 & 851 & 2510 & 263 & 2010 & 40.1 & 232.4 & 0.91 & 0.47 & 0.57 & -13.38 & 196.4 & 1644 \\
\hline Stem mass, $\mathrm{kg} / \mathrm{ha}$ & 2 & 1714 & 1714 & 2093 & 253 & 596 & 14.8 & 34.6 & 0.98 & 0.91 & 0.92 & 0.47 & 0 & 374 \\
\hline$L A I$ & 2 & 2.61 & 2.68 & 3.0 & 0.56 & 1.2 & 21.3 & 51.1 & 0.96 & 0.85 & 0.84 & 0.4 & 0.07 & 0.74 \\
\hline \multicolumn{15}{|c|}{ IUAM8801 } \\
\hline Crop mass, $\mathrm{kg} / \mathrm{ha}$ & 1 & 4220 & 3854 & 4280 & 525 & 872 & 12.4 & 20.6 & 0.99 & 0.98 & 0.97 & 0.91 & -366 & 59.8 \\
\hline Pod mass, kg/ha & 1 & 2043 & 1568 & 2340 & 530 & 678 & 26.0 & 33.2 & 0.96 & 0.96 & 0.86 & 0.78 & -474 & 297 \\
\hline Stem mass, kg/ha & 1 & 1966 & 1888 & 1769 & 216 & 301 & 10.9 & 15.3 & 0.99 & 0.99 & 0.98 & 0.95 & -78.6 & -197 \\
\hline$L A I$ & 1 & 2.98 & 2.81 & 2.94 & 0.39 & 0.98 & 13.3 & 32.7 & 0.99 & 0.94 & 0.95 & 0.72 & -0.17 & -0.04 \\
\hline \multicolumn{15}{|c|}{ IUAM9001 } \\
\hline Crop mass, $\mathrm{kg} / \mathrm{ha}$ & 1 & 4267 & 4511 & 4553 & 454 & 478 & 10.6 & 11.2 & 0.99 & 0.99 & 0.98 & 0.98 & 244 & 285 \\
\hline Pod mass, kg/ha & 1 & 2304 & 2577 & 2575 & 396 & 393 & 17.2 & 17.1 & 0.99 & 0.98 & 0.95 & 0.95 & 272 & 270 \\
\hline Stem mass, $\mathrm{kg} / \mathrm{ha}$ & 1 & 2001 & 2055 & 2082 & 184 & 196 & 9.2 & 9.8 & 0.99 & 0.99 & 0.98 & 0.98 & 53.7 & 80.5 \\
\hline LAI & 1 & 3.33 & 3.31 & 3.36 & 0.23 & 0.22 & 6.9 & 6.7 & 0.99 & 0.99 & 0.99 & 0.99 & -0.03 & 0.03 \\
\hline
\end{tabular}

Table 5. Comparisons of observed and simulated crop mass, pod mass, stem mass, and LAI using the original DSSAT CSM model (CSM) and the coupled DSSAT-HYDRUS-1D model (HYD) for three peanut experiments and their statistical indicators.

\begin{tabular}{|c|c|c|c|c|c|c|c|c|c|c|c|c|c|c|}
\hline \multirow[b]{2}{*}{ Biomass component } & \multirow[b]{2}{*}{ Trt \# } & \multirow[b]{2}{*}{ Mean (Obs.) } & \multicolumn{2}{|c|}{ Mean (Sim.) } & \multicolumn{2}{|c|}{ RMSE } & \multicolumn{2}{|c|}{$n R M S E$} & \multicolumn{2}{|c|}{$d$} & \multicolumn{2}{|c|}{$E F$} & \multicolumn{2}{|c|}{$E$} \\
\hline & & & CSM & HYD & CSM & HYD & $\mathrm{CSM}$ & HYD & CSM & HYD & CSM & HYD & CSM & HYD \\
\hline \multicolumn{15}{|c|}{ UFGA84001 } \\
\hline Crop mass, $\mathrm{kg} / \mathrm{ha}$ & 1 & 6781 & 5806 & 6035 & 1197 & 974 & 17.7 & 14.4 & 0.98 & 0.99 & 0.92 & 0.95 & -975 & 974 \\
\hline Pod mass, kg/ha & 1 & 3290 & 2738 & 2544 & 728 & 1029 & 22.1 & 31.2 & 0.97 & 0.94 & 0.89 & 0.78 & -552 & -746 \\
\hline Stem mass, $\mathrm{kg} / \mathrm{ha}$ & 1 & 2588 & 2236 & 2445 & 472 & 388 & 18.2 & 15.0 & 0.97 & 0.98 & 0.89 & 0.93 & -351 & -143 \\
\hline$L A I$ & 1 & 3.74 & 3.39 & 3.71 & 0.54 & 0.41 & 14.6 & 11.1 & 0.97 & 0.99 & 0.91 & 0.95 & -0.35 & -0.04 \\
\hline Crop mass, kg/ha & 2 & 6686 & 5370 & 6031 & 1654 & 1076 & 24.7 & 16.1 & 0.96 & 0.98 & 0.85 & 0.93 & -1316 & -654 \\
\hline Pod mass, kg/ha & 2 & 3079 & 2406 & 2522 & 838 & 862 & 27.2 & 28.0 & 0.95 & 0.96 & 0.84 & 0.83 & -673 & -558 \\
\hline Stem mass, $\mathrm{kg} / \mathrm{ha}$ & 2 & 2697 & 2146 & 2452 & 799 & 478 & 29.6 & 17.7 & 0.92 & 0.98 & 0.72 & 0.90 & -552 & -245 \\
\hline$L A I$ & 2 & 3.59 & 3.08 & 3.7 & 0.75 & 0.67 & 20.9 & 18.8 & 0.94 & 0.96 & 0.81 & 0.85 & -0.52 & 0.11 \\
\hline \multicolumn{15}{|c|}{ UFGA86001 } \\
\hline Crop mass, $\mathrm{kg} / \mathrm{ha}$ & 1 & 8363 & 6991 & 8251 & 1641 & 734 & 19.6 & 8.8 & 0.96 & 0.99 & 0.87 & 0.97 & -1371 & -112 \\
\hline Pod mass, kg/ha & 1 & 2711 & 2853 & 3187 & 288 & 628 & 10.7 & 23.2 & 0.99 & 0.98 & 0.98 & 0.91 & 141 & 475 \\
\hline Stem mass, $\mathrm{kg} / \mathrm{ha}$ & 1 & 3694 & 2675 & 3281 & 1164 & 631 & 31.5 & 17.1 & 0.87 & 0.96 & 0.57 & 0.87 & -1019 & -413 \\
\hline$L A I$ & 1 & 5.19 & 3.82 & 4.9 & 1.77 & 1.11 & 34.1 & 21.5 & 0.81 & 0.92 & 0.41 & 0.77 & -1.37 & -0.3 \\
\hline \multicolumn{15}{|c|}{ UFGA8701 } \\
\hline Crop mass, kg/ha & 1 & 7336 & 7175 & 8011 & 514 & 890 & 7.0 & 12.1 & 0.99 & 0.99 & 0.98 & 0.95 & -161 & 675 \\
\hline Pod mass, kg/ha & 1 & 3103 & 2873 & 2675 & 458 & 649 & 14.8 & 20.9 & 0.99 & 0.98 & 0.95 & 0.90 & -230 & -427 \\
\hline Stem mass, $\mathrm{kg} / \mathrm{ha}$ & 1 & 2649 & 2826 & 3454 & 300 & 973 & 11.3 & 36.7 & 0.99 & 0.89 & 0.94 & 0.32 & 177 & 805 \\
\hline$L A I$ & 1 & 3.89 & 4.13 & 5.1 & 0.61 & 1.37 & 15.7 & 35.2 & 0.96 & 0.86 & 0.83 & 0.16 & 0.24 & 1.23 \\
\hline
\end{tabular}




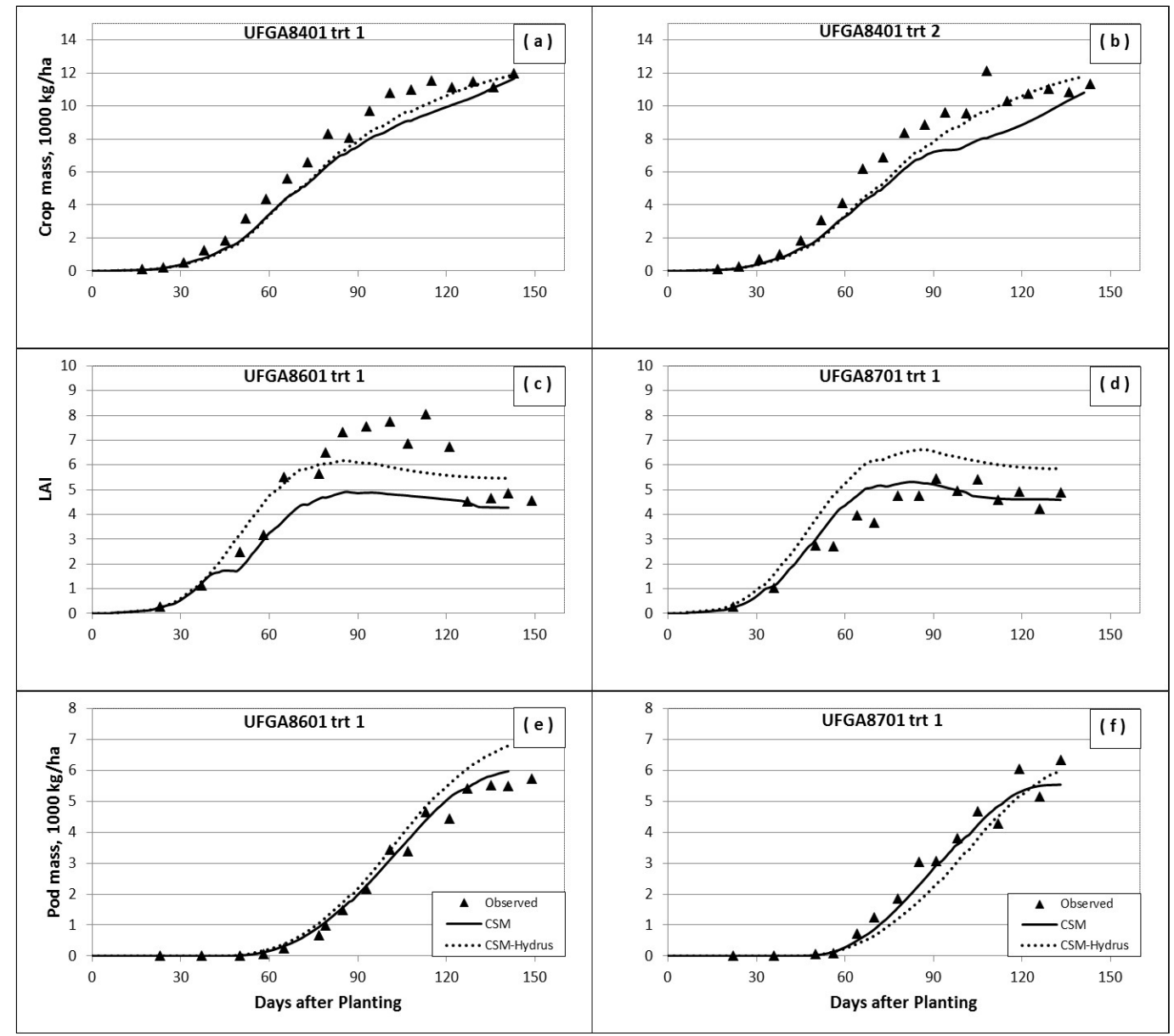

Fig. 9. Simulated and observed crop mass $(\mathrm{a}, \mathrm{b}), L A I \mathrm{~s}(\mathrm{c}, \mathrm{d})$ and pod mass $(\mathrm{e}, \mathrm{f})$ for the Florunner peanut experiments at Gainesville, FL in 1984, 1986, and 1987. Simulations were carried out using the DSSAT CSM model with its tipping bucket approach and the coupled DSSAT-HYDRUS-1D model.

In both treatments of the UFGA8401 peanut experiment, the coupled model performed better with higher values of both the $d$ index and $E F$, and lower values of $n R M S E$, as compared to the original model (Table 5, Fig. 9a,b). Treatment 1 of the UFGA8601 peanut experiment showed again better performance of the coupled model for crop mass, stem mass, and $L A I$. But the coupled model performed slightly worse for pod mass, for which the $d$ index of 0.98 was a fraction lower than 0.99 for the original model, while the $E F$ of 0.91 was also lower than 0.98 for the original model (Table 5, Fig. 9c,e). For treatment 1 of the UFGA8701 peanut experiment, the original model performed better with higher values of the $d$ index and $E F$. Both models had the same $d$ index value $(0.99)$ for crop mass, although the RMSE for the original model was better as compared to the coupled model: $514 \mathrm{~kg} / \mathrm{ha}$ and $890 \mathrm{~kg} / \mathrm{ha}$, respectively (Table 5 and Fig 9d,f).

The various DSSAT CSM and DSSAT-HYDRUS-1D simulations of soybean and peanut crop production overall showed differences when applied to water-limiting conditions using several different datasets for two locations. As shown above, the coupled model in general predicted less evapotranspiration and higher water contents in the soil profile, which resulted in less water stress, higher $L A I$ values and more biomass than the original DSSAT CSM model. While the simulations as such showed the great potential of the coupled model, several improvements may be possible in the analysis of the experiments discussed in this study. These include getting better soil texture data (and hydraulic property information) especially for the soybean experiment at ISU, improving root length distribution data, and improving the partitioning of potential ET into potential evaporation $\left(E_{p}\right)$ and transpiration $\left(T_{p}\right)$. Availability of such information should further improve the reliability and accuracy of the predictions.

\section{CONCLUSIONS}

HYDRUS-1D was coupled in this study with the Cropping System Model (CSM) of DSSAT V4.6 to simulate soil water dynamics. Simulations with the coupled model were compared with results obtained with the original model that uses a tipping bucket approach for soil water modeling. Performance of the two models was evaluated in terms of simulated soil water contents, evapotranspiration, and various crop yield components. Results showed that the coupled model provided satisfactory simulations of soil water content changes as well as the plant growth. However, the two models provided different predictions for crop, pod, seed, and stem mass, and the crop $L A I$, especially under water-limited conditions for soybean in Iowa and Florida and peanut in Florida. The coupled model, in that case, simulated insufficient yield reductions under drought, possibly related to its lower evapotranspiration rate during the full canopy phase. The coupled model produced significantly different results for actual evapotranspiration rates, being higher during an early canopy phase, but lower during the full cano- 
py phase when LAI was high. These differences in evapotranspiration rates contributed to differences in simulated soil water contents at different times of the season, even though the dynamics of water movement by the coupled model was simulated well. Each of the two approaches to soil water modeling has particular advantages and disadvantages, which should be tested in further studies against more comprehensive datasets related to the soil and plant water regimes.

\section{REFERENCES}

Boote, K. J., Sau, F., Hoogenboom, G., Jones, J.W., 2008. Experience with Water Balance, Evapotranspiration, and Predictions of Water Stress Effects in the CROPGRO Model. Response of crops to limited water: Understanding and modeling water stress effects on plant growth processes. Advances in Agricultural Systems Modeling Series 1. ASA, CSSA, SSSA, 677 S. Segoe Rd., Madison, WI 53711, USA. pp. 59-103.

Boote, K.J., Jones, J.W., Hoogenboom, G., White, J.W., 2010. The role of crop systems simulation in agriculture and environment. Int. J. Agric. Environ. Inf. Syst., 1, 41-54.

Bristow, K.L., Hopmans, J.W., Cote, C.M., Charlesworth, P.B., Thorburn, P.J., Cook, F.J., 2002. Development of improved water and nutrient management strategies through strategic modeling. In: Proc. 17th WCSS, Thailand, pp. 14-21.

Dabach, C., Shani, U., Lazarovitch, N., 2015. Optimal tensiometer placement for high-frequency subsurface drip irrigation management in heterogeneous soils. Agric. Water Manag., 152, 91-98.

David, O., Markstrom, S.L., Rojas, K.W., Ahuja, L.R., Schneider, I.W., 2002. The Object Modeling System. In: Ahuja, L.R., Ma, L., Howell, T.A. (Eds): Agricultural System Models in Field Research and Technology Transfer. Lewis Publishers, Boca Raton, FL, 317-330.

Dokoohaki, H., Gheysari, M., Mousavi, S., Zand-Parsa, S., Miguez, F., Archontoulis, S., Hoogenboom, G., 2016. Coupling and testing a new soil water module in DSSAT CERES-Maize model for maize production under semi-arid condition. Agric. Water Manag., 163, 90-99.

Feddes, R. A., Kowalik, P. J., Zaradny, H., 1978. Simulation of field water use and crop yield. In: Simulation Monograph, Pudoc, Wageningen, The Netherlands, pp. 9-30.

Gärdenäs, A.I., Hopmans, J.W., Hanson, B. R., Šimůnek, J., 2005. Two-dimensional modeling of nitrate leaching for various fertigation scenarios under micro-irrigation. Agric. Water Manag., 74, 219-242.

Gheysari, M., Mirlatifi, S.M., Homaee, M., Asadi, M.E., Hoogenboom, G., 2009. Nitrate leaching in a silage maize field under different irrigation and nitrogen fertilizer rates. Agric. Water Manag., 96, 946-954.

Gijsman, A.J., Jagtap, S.S., Jones, J.W., 2002a. Wading through a swamp of complete confusion: How to choose a method for estimating soil water retention parameters for crop models. Eur. J. Agron., 18, 75-105.

Gijsman, A.J., Hoogenboom, G., Parton, W.J., Kerridge, P.C., 2002b. Modifying DSSAT crop models for low-input agricultural systems using a soil organic matter residue module from CENTURY. Agron. J., 94, 462-474.

Gregersen, J.B., Gijsbers, P.J., Westen, S.J., 2007. OpenMI: open modeling interface. J. Hydroinf., 9, 3, 175-191.

Groenendyk, D., Thorp, K.R., Ferre, P.A., Crow, W.T., 2012. Testing an Ensemble Kalman Filter for assimilation of soil moisture into HYDRUS 1D and Coupled Crop Model. In:
American Geophysical Union, Fall Meeting 2012, Abstract \#H33F-1382.

Han, M., Zhao, C., Šimůnek, J., Feng, G., 2015. Evaluating the impact of groundwater on cotton growth and root zone water balance using Hydrus-1D coupled with a crop growth model. Agric. Water Manag., 160, 64-75, DOI: 10.1016/j.agwat.2015.06.028.

Hanson, B.R., Šimůnek, J., Hopmans, J.W., 2008. Leaching with subsurface drip irrigation under saline, shallow groundwater conditions. Vadose Zone Journal, 7, 2, 810818, DOI: 10.2136/VZJ2007.0053.

Harbaugh, A.W., Banta, E.R., Hill, M.C., McDonald, M.G., 2000. MODFLOW-2000, the U.S. Geological Survey modular ground-water model user guide to modularization concepts and the ground-water flow process. USGS, Denver, CO.

Hartmann, A., Šimůnek, J., Aidoo, M.K., Seidel, S. J., Lazarovitch, N., 2017. Modeling root growth as a function of different environmental stresses using HYDRUS. Vadose Zone Journal, 16, DOI: 10.2136/vzj2017.02.0040, (accepted June 13 2017).

Hoogenboom, G., Jones, J.W., Wilkens, P.W., Porter, C.H., Boote, K.J., Hunt, L.A., Singh, U., Lizaso, J.I., White, J.W., Uryasev, O., Ogoshi, R., Koo, J., Shelia, V., Tsuji, V., 2015. Decision Support System for Agrotechnology Transfer (DSSAT) Version 4.6 (www.DSSAT.net). DSSAT Foundation, Prosser, Washington.

Ines, A.V.M., Droogers, P., Makin, I.W., Das Gupta, A., 2001. Crop growth and soil water balance modeling to explore water management options. IWMI Working Paper 22. Colombo, Sri Lanka: International Water Management Institute. 26 p.

Jones, J.W., Hoogenboom, G., Porter, C.H., Boote, K.J., Batchelor, W.D., Hunt, L.A., Wilkens, P.W., Singh, U., Gijsman, A.J., Ritchie, J.T., 2003. DSSAT Cropping System Model. Europ. J. Agron., 18, 235-265.

Kandelous, M.M., Kamai, T., Vrugt, J.A., Šimůnek, J., Hanson, B.R., Hopmans, J.W., 2012. Evaluation of subsurface drip irrigation design and management parameters for alfalfa. Agric. Water Manag., 109, 81-93.

Li, Y., Zou, Q., Zhou, J., Zhang, G., Chen, C., Wang, J., 2014. Assimilating remote sensing information into a coupled hydrology-crop growth model to estimate regional maize yield in arid regions. Ecological Modelling, 291, 15-27.

Liu, H.L., Yang, J.Y., Drury, C.F., Reynolds, W.D., Tan, C.S., Bai, Y.L., He, P., Jin, J., Hoogenboom, G., 2010. Using the DSSAT-CERES-Maize model to simulate crop yield and nitrogen cycling in fields under long-term continuous maize production. Nutr. Cycl. Agroecosys., 1-16, DOI: 10.1007/s10705-010-9396-y.

Liu, H.L., Yang, J.Y., Tan, C.S., Drury, C.F., Reynolds, W.D., Zhang, T.Q., Bai, Y.L., Jin, Y.L., He, P., Hoogenboom, G., 2011. Simulating water content, crop yield and nitrate-N loss under free and controlled tile drainage with subsurface irrigation using the DSSAT model. Agric. Water Manage., 98, 1105-1111.

Loague, K., Green, R.E., 1991. Statistical and graphical methods for evaluating solute transport models: overview and application. J. Contam. Hydrol., 7, 51-73.

Nash, J.E., Sutcliffe, J.V., 1970. River flow forecasting through conceptual models. part I - A discussion of principles. J. Hydrol., 10, 282-290.

Mualem, Y., 1976. A new model for predicting the hydraulic conductivity of unsaturated porous media. Water Resources Research, 12, 3, 513-522. 
Mullen, J.D., Yu, Y., Hoogenboom, G., 2009. Estimating the demand for irrigation water in a humid climate: A case study from the southeastern United States. Agric. Water Manage., 96, 1421-1428.

Pachepsky, Y., Guber, A., Jacques, D., Šimůnek, J., van Genuchten, M.Th., Nicholson, T., Cady, R., 2006. Information content and complexity of simulated soil water fluxes. Geoderma, 134, 253-266.

Peña-Haro, S., Zhou, J., Zhang, G.F., Chen, C., Stauffer, F., Kinzelbach W., 2012. A multi-approach framework to couple independent models for simulating the interaction between crop growth and unsaturated-saturated flow processes. In: Seppelt, R., Voinov, A.A., Lange, S., Bankamp D. (Eds.): International Environmental Modelling and Software Society (iEMSs) 2012 International Congress on Environmental Modelling and Software. Managing Resources of a Limited Planet: Pathways and Visions under Uncertainty. Sixth Biennial Meeting, Leipzig, Germany, pp. 1224-1231. http://www.iemss.org/society/index.php/iemss-2012proceedings. ISBN: 978-88-9035-742-8.

Porter, C.H., Jones, J.W., Hoogenboom, G., Wilkens, P.W., Ritchie, J.T., Pickering, N.B., Boote, K.J., Baer, B., 2004. DSSAT v4 soil water balance module. In: Jones, J.W. et al. (Eds.): Decision support system for agrotechnology transfer Version 4.0, Vol. 4 DSSAT v4: Crop model documentation. Univ. of Hawaii, Honolulu, HI, pp. 1-23.

Priestley, C.H.B., Taylor. R.J., 1972. On the assessment of surface heat and evaporation using large scale parameters. Mon. Weather Rev., 100, 81-92.

Ritchie, J.T., 1972. A model for predicting evaporation from a row crop with incomplete cover. Water Resources Research, 8, 1204-1213.

Ritchie, J.T., 1981a. Water dynamics in the soil-plantatmosphere. Plants and Soil, 58, 81-96.

Ritchie, J.T., 1981b. Soil water availability. Plants and Soil, 58, 327-338.

Ritchie, J.T., 1985. A user-oriented model of the soil water balance in wheat. p. 293-305. In: Fry, E., Atkin, T.K. (Eds): Wheat Growth and Modeling. NATO-ASI Series, Plenum Press.

Ritchie, J.T., 1998. Soil water balance and plant water stress. In Tsuji, G.Y., Hoogenboom, G., Thornton, P.K. (Eds): Understanding Options of Agricultural Production. Kluwer Academic Publishers and International Consortium for Agricultural Systems Applications, Dordrecht, The Netherlands, pp. 41-54.

Ritchie, J.T., Porter, C.H., Judge, J., Jones, W.J., Suleiman, A.A., 2009. Extension of an existing model for soil water evaporation and redistribution under high water content conditions. Soil Sci. Soc. Am. J., 73, 792-801.

Sarkar, R., 2009. Use of DSSAT to model cropping systems. CAB Reviews: Perspectives in Agriculture, Veterinary Science, Nutrition and Natural Resources, 4, No. 025.

Saxton, K.E., Rawls, W.J., Romberger, J.S., Papendick, R.I., 1986. Estimating generalized soil-water characteristics from texture. Soil Sci. Soc. Am. J., 50, 1031-1036.

Scanlon, B.R., Christman, M., Reedy, R.C., Porro, I., Šimůnek, J., Flerchinger, G.F., 2002. Intercode comparisons for simulating water balance of surficial sediments in semiarid regions. Water Resources Research, 38, 12, 1323, 59.1-59.16. DOI: 10.1029/2001WR001233.
Seo, H., Šimůnek, J., Poeter, E., 2007. Documentation of the HYDRUS package for MODFLOW-2000, the US Geological Survey modular ground-water model. GWMI 2007-01. Int. Ground Water Modeling Ctr, Colorado School of Mines, Golden, pp. 1-98.

Šimůnek, J., Hopmans, J.W., 2009. Modeling compensated root water and nutrient uptake. Ecological Modeling, 220, 4, 505-521. DOI:10.1016/j.ecolmodel.2008.11.004.

Šimůnek, J., van Genuchten, M.T., Šejna, M., 2008. Development and applications of the HYDRUS and STANMOD software packages and related codes. Vadose Zone Journal, 7, 2, 587-600. DOI: 10.2136/vzj2007.0077.

Šimůnek, J., van Genuchten, M.Th., Šejna, M., 2016. Recent developments and applications of the HYDRUS computer software packages. Vadose Zone Journal, 15, 7, pp. 25. DOI: 10.2136/vzj2016.04.0033.

Sophocleous, M., Koelliker, J.K., Govindaraju, R.S., Birdie, T., Ramireddygari, S.R., Perkins, S.P., 1999. Integrated numerical modeling for basin-wide water management: The case of the Rattlesnake Creek basin in south-central Kansas. Journal of Hydrology, 214, 1-4, 179-196.

Suleiman, A.A., Ritchie J.T., 2003. Modeling soil water redistribution during second-stage evaporation. Soil Sci. Soc. Am. J., 67, 377-386.

Twarakavi, N.K.C., Šimůnek, J., Seo, S., 2008. Evaluating interactions between groundwater and vadose zone using the HYDRUS-Based Flow Package for MODFLOW. Vadose Zone Journal, 7, 757-768.

van Genuchten, M. Th., 1980. A closed-form equation for predicting the hydraulic conductivity of unsaturated soils. Soil Sci. Soc. Am. J., 44, 892-898.

van Walsum, P.E.V., 2011. Influence of feedbacks from simulated crop growth on integrated regional hydrologic simulations under climate scenarios. Hydrol. Earth Syst. Sci. Discuss., 8, 10151-10193.

Vrugt, J. A., Hopmans, J. W., Šimůnek, J., 2001a. Calibration of a two-dimensional root water uptake model, Soil Science Society of America Journal, 65, 4, 1027-1037.

Vrugt, J.A., van Wijk, M.T., Hopmans, J.W., Šimůnek, J., 2001b. One-, two-, and three-dimensional root water uptake functions for transient modeling. Water Resources Research, $37,10,2457-2470$.

Wang, J., Huang, G, Zhan, B., Mohanty, P., Zheng, J., Huang, Q., Xu, X., 2014. Evaluation of soil water dynamics and crop yield under furrow irrigation with a two-dimensional flow and crop growth coupled model. Agric. Water Manag., $141,10-22$.

Williams, J.R. 1991. Runoff and water erosion. In: Hanks, R.J., Richie, J.T. (Eds): Modeling Soil and Plant Systems. Agronomy Monograph 31. Madison, Wisconsin, USA: American Society of Agronomy, pp. 439-455.

Willmott, C.J., Ackleson, S.G., Davis, R.E., Feddema, J.J., Klink, K.M., Legates, D.R., O'Donnell, J., Rowe, C.M., 1985. Statistics for the evaluation and comparison of models. J. Geophys. Res., 90, 8995-9005.

Zhou, J., Cheng, G., Li, X., Hu, B. X., Wang, G., 2012. Numerical modeling of wheat irrigation using coupled HYDRUS and WOFOST models. Soil Sci. Soc. Am. J., 76, 2, 648662. DOI: 10.2136/sssaj2010.0467.

Received 23 September 2017 Accepted 11 December 2017

Note: Colour version of Figures can be found in the web version of this article. 